CuPAUAM. 15-1988

\title{
RECURSOS POTENCIALES Y APROVECHAMIENTO DEL ENTORNO EN LA CULTURA DEL ARGAR
}

\author{
CARIDAD MAROTO BARCHINO \\ Becaria del programa colaboración U.A.M./Caja Madrid. \\ Dpto. de Prehistoria y Arqueología
}

\section{Resumen}

El propósito de este trabajo es incidir en cómo se establece la relación hombre-medio natural en un grupo de asentamientos de la cultura del Argar en la provincia de Almería. Para ello describimos los recursos potenciales que ofrece el entorno en que se ubican dichos hábitats. El aprovechamiento de dicho entorno queda reflejado en los restos materiales y evidencias arqueológicas que se registran para cada uno de los yacimientos. La explotación diferencial, tanto cualitativa como cuantativamente considerada, define el sistema económico de la cultura argárica.

\section{Summary}

The purpose of this work is to show how to establish the relation between man and natural habitat in a settlement group of the Argar culture in the province of Almeria. In order to our aim, we are going to describe the potencial resources that the environment where these habitats are placed offers. How to these environments were exploted is showed by the material rests and archeologics evidences which are registered in each deposit. The differential explotation, qualitative and quantitatively considerated, defines economic system Argar culture's.

La cultura del Argar, después de más de un siglo desde que se produjo su descubrimiento, continúa en proceso de definición, aún cuando pudiera parecer que está casi todo explicado. Bien es verdad, que los estudios acerca de los restos materiales (RUIZ GÁLVEZ, 1977; SCHUBART 1973, 1975), y sólo éstos, son numerosos. Nuevos hallazgos vienen a completar el cuadro en los últimos veinte años (PÉREZ Y PAOLETTI, 1977; MENDOZA-PAREJA, 1975), algunas veces acompañados de oportunas excavaciones, siempre necesarias, pero insuficientes.

No obstante, el proceso de interpretación, explicación, que no descripción, ha producido algunos frutos en los últimos años que han abierto un debate en torno a cuestiones ecológi- 
cas y socioeconómicas que pueden ampliar el reducido horizonte de investigación existente. Trabajos como los de LULL (1983) o GILMAN y THORNES (1985) plantean una nueva lectura de los asentamientos. Por lo que respecta a sus hipótesis y conclusiones, frente a cuestiones aceptadas mayoritariamente en la historiografía como la jerarquización de asentamientos, permanecen discutidas otras como la presencia o ausencia de irrigación, o el espinoso asunto de las variables climáticas. Requieren sin embargo una revisión las deducciones acerca de la importancia de las distintas actividades económicas y cómo éstas están representadas en las distintas provincias. Mucho queda todavía por plantear y desarrollar, matizar y porfiar.

Es en esta dialéctica en la que queremos terciar a partir de los planteamientos teóricos de la llamada Arqueología Espacial o análisis del entorno y captación de los yacimientos. Para ello hemos elegido un grupo de asentamientos, concretamente Lugarico Viejo, Fuente Vermeja, El Argar y Fuente Alamo. Proponemos un modelo de estudio de los mismos que contribuya a aclarar el modo según el cual ante unos determinados recursos potenciales (que no tienen porqué ser los mismos para todos) el hombre explotó unos y no otros, y más unos que otros. Entendemos que son estos parámetros algunos de los que pueden ayudar a comprender el peculiar sistema económico argárico, convenientemente articulados con la lectura de los restos y evidencias arqueológicas. Tanto más comprenderemos la cultura argárica cuantos más datos tengamos a propósito del medio en que se desarrolló y cómo este fue modificado por la acción antrópica.

Por lo que respecta en particular a los yacimientos escogidos debemos subrayar que los materiales y evidencias con los que contamos proceden de las excavaciones realizadas por los hermanos Siret en todos los casos y por aquellas que en 1977 y 1979 llevaron a cabo SCHUBART Y ARTEAGA en Fuente Alamo. Las repetidas menciones que haremos a lo largo de este artículo, a dichos restos recuperados o a su situación, están convenientemente publicadas en "Las primeras edades del metal en el Sudeste de España", 1890 obra de los hermanos Siret, y en los artículos que en 1980, 1981 y 1983 han escrito SCHUBART Y ARTEAGA con respecto a Fuente Alamo.

El comienzo de nuestro análisis debe pasar por una localización a nivel peninsular, regional y puntual de cada uno de los hábitats, a continuación analizaremos los distintos recursos que el entorno inmediato ofrece hasta una hora aproximada de camino, de forma convencional, desde el yacimiento, que se correspondería a nivel teórico con unos $5 \mathrm{Kms}$. en todas las direcciones.

\section{UBICACION}

Estos asentamientos están localizados en la provincia de Almería, al NE. de la misma, en los términos municipales de Antas en el caso de El Argar, Lugarico Viejo y Fuente Vermeja, siendo Cuevas de Almanzora el correspondiente a Fuente Alamo (Mapa Topográfico Nacional, hojas 996, 997, 1.014 y 1015). Es decir, en la llamada Fachada Litoral Almeriense, que está delimitada por la costa y las últimas estribaciones del Sistema Bético. La comarca natural de todos ellos es la llamada Vera y la cuenca hidrográfica en que se instalan es la 
del Antas-Jauro para Lugarico Viejo, Fuente Vermeja y el Argar, mientras que Fuente Alamo lo hace en la del Almanzora (DíAZ ALVAREZ, 1984).

La latitud en la que quedarían comprendidos en conjunto es entre $37^{\circ} 20^{\prime}$ (Fuente Alamo) y $37^{\circ} 15^{\prime}$ (Argar) Norte. Mientras que la longitud Este con respecto al meridiano de Madrid está definida entre $1^{\circ} 43^{\prime} 50^{\prime \prime}$ (Lugarico Viejo) y $1^{\circ} 50^{\prime}$ (Fuente Alamo). Para situarnos podemos dibujar una figura acotada al Este por la costa, al Norte por las Sierras de Almagro y Almagrera, al Oeste por las sierras de Filabres y Bédar y al Sur por la cuenca del Aguas y Sierra Cabrera.

Una vez establecidas estas coordenadas conviene localizar puntualmente cada uno de los asentamientos como hace R. Colmenarejo (1986) y añadir la distancia entre los mismos, con el fin de alcanzar una mayor precisión y matizar las diferencias entre ellos, así como establecer los patrones de asentamiento. De esta forma:

Lugarico Viejo: El más occidental de todos, se encuentra en la margen derecha del JauroAntas en uno de los recodos del mismo y rodeado por éste al N. y NW. Se eleva 210 metros s.n.m. Unos 17,5 kilómetros lo separan de la costa. Ocupa una cima amesetada dentro del conjunto de las lomas del Perro (Sierra de Bédar). Al N. y NE. se encuentra Sierra Lisbona. Escarpes rocosos lo defienden naturalmente siendo más accesible por el N.-NE. con pendientes más suaves hacia el río. Fuente Vermeja se halla a $1 \mathrm{Km}$. hacia el NE., el Argar a unos cuatro en dirección Este y a unos 12,200 Kms. en dirección NE. está Fuente Alamo.

Fuente Vermeja: Se eleva 190 metros s.n.m., situado en una ladera descendente en la margen izquierda del Antas-Jauro previa a una zona amesetada a los pies de Sierra Lisbona (al NW). A 16,5 kilómetros del mar y a 2,6 de la Rambla de Cayete al Este. Dista del Argar (en el SE.) 3,5 Kms., de Fuente Alamo al NE. 11,2 Kms. Las márgenes se presentan cortadas a pico, especialmente al N. y W. complementado por gargantas (ramblas) al Este en virtud del abarrancamiento de la zona fruto de la escorrentía ocasional hacia el río.

El Argar: Se escogió como asiento una meseta sobre el Antas en su margen izquierda a $108 \mathrm{mts}$. s.n.m. Se extiende por las laderas existiendo escarpes abruptos en el W. con pendientes del 25 al $40 \%$. Se ubica a la altura en la que la rambla de Cayete se une al AntasJauro, lo separan de ésta unos 300 metros. A unos 12,700 Kms., está la costa. El Argar supone una de las primeras elevaciones, tras la llanura costera, que se inician con el cerro del Espíritu Santo en Vera. Fuente Alamo está a unos $10 \mathrm{Kms}$.

Fuente Alamo: En la margen izquierda del río Almanzora, a 3,5 Kms. del mismo y en las primeras estribaciones que dan paso a la Sierra de Almagro. Se dispone en un cabezo ocupando la cima y ladera alcanzando los 261 metros. Aparece jalonado a E. y W. por sendas vertientes escarpadas mientras que a W. y Sur las pendientes son más suaves ascendiendo en la primera orientación y descendiendo en la parte meridional. El acceso se realiza a partir de las ramblas de Artesica y Joaquín que vierten sus cauces al Almanzora. La costa se divisa a 14,5 Kms. en línea recta en dirección Este aún cuando la distancia puede ser menor de $11,5 \mathrm{Kms}$. en dirección SE. 
Para El Argar, Fuente Vermeja y Lugarico Viejo las pendientes varían en el entorno del 5 al $15 \%$. En el caso de Fuente Alamo, y debido a la presencia de la Sierra de Almagro, superan el $15 \%$.

En resumen:

- En la elección de estos asentamientos primó la ubicación en puntos elevados con respecto al entorno.

- El acceso a los mismos está dificultado en una o varias vertientes por escarpes rocosos.

- Se eligieron las cimas, produciéndose también la ocupación de las laderas en el caso de Fuente Alamo y El Argar. Tan sólo Fuente Vermeja se ubicó únicamente en la ladera.

- Se procuró que en las proximidades existiera una corriente de agua de mayor o menor envergadura y con un régimen relativamente regular.

\section{CLIMATOLOGIA}

Insuficientemente estudiada con respecto al segundo milenio, es objeto de diversas hipótesis (LULL, 1983; GILMAN Y THORNES, 1985) en tanto que pone una de las bases del desarrollo de los recursos orgánicos junto con la litología, geomorfología y geología. Nosotros nos limitaremos a dar los datos referentes al presente, en tanto no exista un trabajo específico para este tema y esta zona. De cualquier forma, si aceptamos un cambio en las precipitaciones tenemos que atribuirlo a la acción antrópica que analizaremos más adelante.

Si hacemos referencia a los índices térmicos (DÍAZ ALVAREZ, 1981, 1984) tenemos primero que localizar los asentamientos en una zona de clima subdesértico con elevadas temperaturas medias anuales especialmente en los meses de verano, los mínimos corresponden a Enero y Febrero, siendo de unos $16^{\circ} \mathrm{C}$ la oscilación anual. Con respecto a las precipitaciones no se alcanzan los $300 \mathrm{~mm}$. anuales repartidos en 10 o 30 días lluviosos. Esto es, la aridez es máxima lo que sumado a las elevadas temperaturas provoca uno de los mayores índices de evaporación en la península, en especial en el caso de Cuevas de Almanzora.

En concreto El Argar y Fuente Vermeja tienen una temperatura media anual superior a los $18^{\circ} \mathrm{C}$, mientras que Lugarico Viejo oscila entre los $17^{\circ}$ y $18^{\circ}$ al igual que Fuente Alamo. Con respecto a las precipitaciones, el grupo del Antas (Lugarico Viejo, Fuente Vermeja y El Argar) reciben $235 \mathrm{~mm}$. anuales (Gilman, 1985, 173) mientras que en Fuente Alamo los indices son de $250 \mathrm{~mm}$.

\section{GEOLOGIA, LITOLOGIA Y GEOMORFOLOGIA}

Los asentamientos que estudiamos han sido poco interpretados desde este punto de vista, tal vez por ello se llega a generalizaciones como la afirmación de que los poblados argáricos se asentaron en zonas ineptas desde el punto de vista agrícola (PELliCER CATALÁN, 1986).

Por el contrario, el que correspondan a unidades morfológicas miocénicas (Mapa Geológico de España, 996, 997, 1014 y 1015) que aparecen afectadas por los procesos postorogéni- 
cos de depósitos cuaternarios tanto en la Cuenca del Almanzora como en Antas y (que se extienden hacia el Norte del área considerada) matiza la cuestión. Así Fuente Alamo estaría en el límite de la unidad Alpujárride, mientras que el resto estaría comprendido en el complejo Nevado-Filabres.

Por su parte la litología (Mapa Geotécnico General Almería-Garrucha) viene a completar el cuadro. Lugarico Viejo, Fuente Vermeja y el Argar comprenden materiales tales como margas, calizas, areniscas, miocénicos todos ellos. En las proximidades arenas, arcillas, limos y gravas con aparición de elementos lajosos. En concreto para Lugarico Viejo (Siret, 1890) se citan calizas en la base y aluviones cuaternarios en la cima con cuarcitas y micacitas. Margas de yeso entre las que se encuentra sulfato de cal cristalizado junto con aluviones, conglomerados y arena micácea en el caso del Argar. Fuente Vermeja se asienta sobre calizas cristalinas, cuarcitas y pizarras cubiertas por aluviones cuaternarios de limo arcilloso. En el caso de Fuente Alamo los componentes litológicos varían en parte en la zona siendo predominantes las pizarras cuarzosas, los micasquistos y micacitas pudiendo presentarse también yesos. En el asiento en concreto, margas y conglomerados aparecen alternados con basaltos. Pudingas y cal los cubren.

En consecuencia, en el grupo del Jauro-Antas (Mapa Geotécnico General Almería-Garrucha) los materiales provocan una sucesión de lomas y barrancos en cuya formación colaboran las lluvias torrenciales. Para el entorno de Fuente Alamo la aparición de lomas y zonas encajadas contrasta con las zonas suaves en que dominan los micasquistos. No obstante el relieve es más acusado y fracturado que para el resto de los asentamientos.

Sin embargo la base litológica y la cantidad de precipitaciones supusieron la formación de este característico paisaje que viene a reforzar la idea de que la irregularidad del agua de las ramblas no debió ser tal en otros tiempos.

\section{HIDROLOGIA}

En este sentido, tendremos en cuenta la distribución espacial de estos cursos de agua (Mapa Topográfico nacional 996, 997, 1.014, 1.015) con la intención de destacar la proximidad o lejanía, la posibilidad de abastecimiento, aunque en el grupo que depende del Jauro-Antas (Fuente Vermeja, El Argar y Lugarico Viejo) (Figura 1.) podemos afirmar que en la actualidad el régimen de precipitaciones y la elevada evapotranspiración determinan la irregularidad y escasez del caudal, aun cuando hay que sumar las numerosas aportaciones de las ramblas que canalizan las precipitaciones de las sierras de Lisbona y Bédar.

Pasando el análisis, la más importante de estas ramblas es la de Cayete que discurre de Norte a Sur y vierte al río Jauro-Antas a la altura del término de Antas precisamente, esto es, en la proximidad de El Argar. A su vez esta rambla recoge las aguas de Sierra Lisbona a través de la rambla del Serrón. Dentro de un supuesto marco teórico de $5 \mathrm{Kms}$. abarcables a partir del yacimiento citado aparecen también en la zona sur la Rambla de la Salaosa y del Barranco de la Cantera que parten de las estribaciones de la sierra de Bédar. Una rambla tricéfala al Este del Argar vierte al Antas procedente de la elevaciones circundantes. 


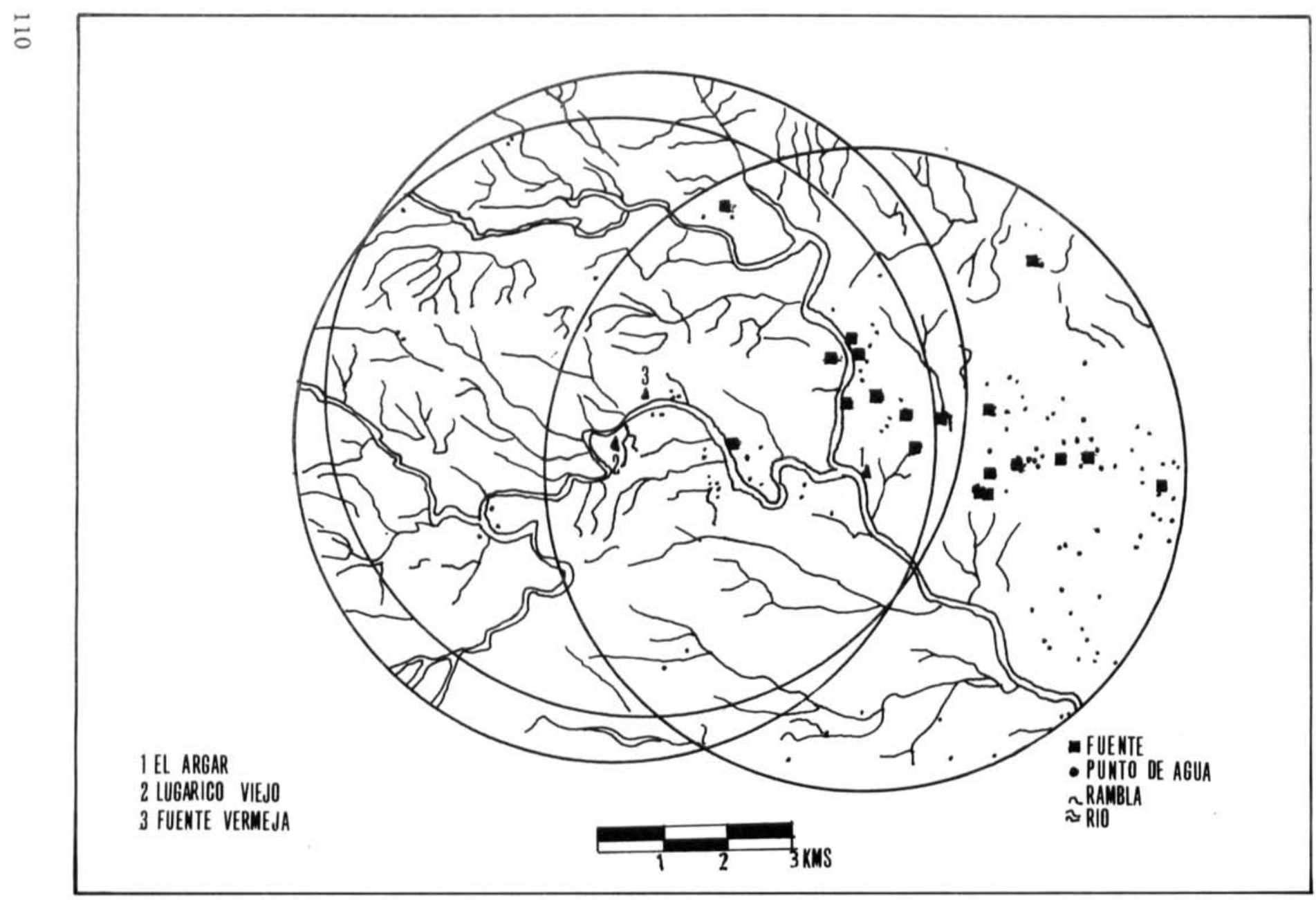

FIG. 1. - Hidrología. 
Además el ámbito del Argar comprende numerosos pozos, fuentes, actuales desde luego, en el cuadrante NE. en una singular concentración que supone la existencia de unas reservas subterráneas importantes.

Por lo que respecta a Lugarico Viejo y Fuente Vermeja podemos apreciar que el número de ramblas en sus proximidades crece en número con respecto al Argar, aún cuando la importancia en caudal de las mismas es menor. Así al SW. de ambos yacimientos encontraremos como la única principal la Rambla de Lisbona. En Lugarico Viejo una rambla cruza por el Este siendo la más próxima al yacimiento. Fuente Vermeja suple la inexistencia de ramblas al pie del yacimiento con una fuente que le da su nombre.

El número de puntos de agua para estos yacimientos es menor con mucho que en el Argar, aunque no obstante al SE. de los mismos se localiza un grupo importante equidistante respecto al Argar. Puntos aislados se localizan a gran distancia al N., SW. (Rambla Lisbona) y al Sur de estos yacimientos, por lo que su importancia es mínima.

Por su parte Fuente Alamo en la cuenca del Almanzora se encuentra a 3,5 Kms. del río frente a la proximidad de Lugarico Viejo, Fuente Vermeja y el Argar al Jauro-Antas (Figura 2.). El Almanzora con un régimen pluvio-subtropical (DíAZ ALVAREZ, 1981, 246) lleva agua gran número de meses siendo algunos años de corriente contínua. Las precipitaciones caídas en las estribaciones de la Sierra de Almagro determinan la disposición de las ramblas de Norte a Sur. Así podemos destacar como las más importantes, si las nombramos de Este a Oeste en relación al yacimiento, la rambla de la Torre, de las Mateas, el barranco del levita, la rambla de Artesica, de Gomara (al W. del yacimiento y la más caudalosa).

De otro lado, la mayor concentración de pozos de agua se localiza en las proximidades del río al Sur del yacimiento. Una fuente da nombre al asiento al situarse al pie del mismo. Otras fuentes importantes serían la fuente del Pino y Fuente Espín al NW. y a gran distancia del yacimiento.

Estas serían en suma las posibilidades más rentables por su fácil explotación pero tenemos que nombrar también la presencia de acuíferos en la zona del Antas, principalmente, que obedece a los terrenos arcillosos y de margas que se comportan como impermeables, estando situados a pequeña profundidad y con potencia-limitada. Aunque aparecen también materiales impermeables en la zona de Fuente Alamo, la aparición de grietas dificulta la acumulación. Esta característica diferencial determina también en otro sentido las dificultades o no de drenaje de la zona. Así Fuente Vermeja y el Argar presentan un mayor encharcamiento debido a sus materiales semipermeables frente a Lugarico Viejo con mayor impermeabilización que facilita el drenaje así como la acumulación en el caso de la existencia de vaguadas. (Mapa Geotécnico General Almería-Garrucha).

Faltaría en este bosquejo hacer una mención a la existencia de una posible "cisterna" en Fuente Alamo (SCHUBART-ARTEAGA, 1983b, 57) que estaría en relación con lo expuesto más arriba acerca de los materiales y la posible cantidad de agua recogida (en mayor medida que en el resto de los yacimientos). Esta solución técnica, aunque no desconocida en otros yacimientos de la cultura argárica, parece corresponder a los últimos momentos del Bronce argárico del yacimiento y desconocemos su utilización. Pudo ser utilizada como abrevadero con mayor razón en función de la existencia de fuentes naturales para el consumo humano 

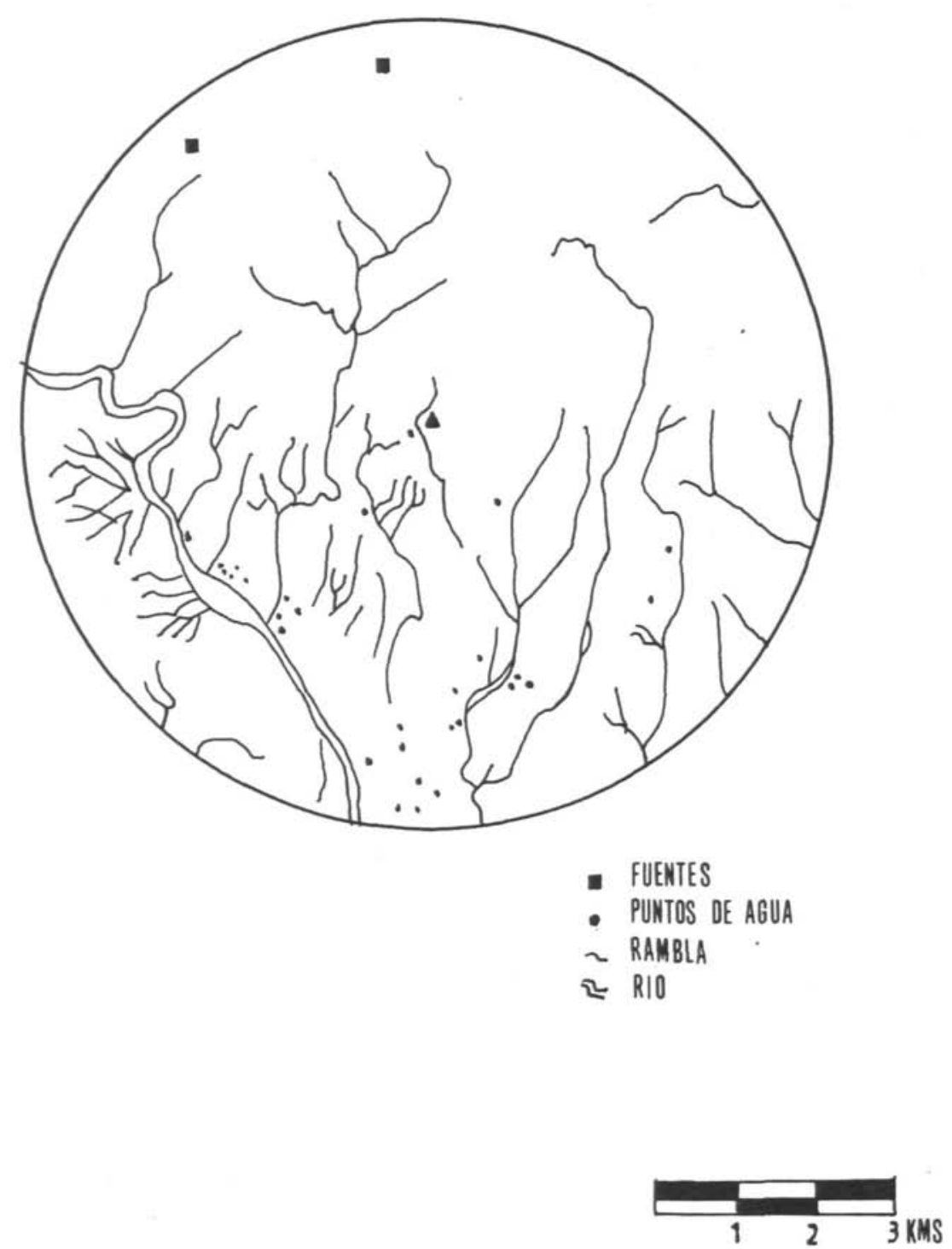

FIG. 2. - Hidrología de Fuente Alamo. 
en los flancos oriental y occidental del cerro, pero bien pudiera ser que cubriera las necesidades humanas en los meses de verano, cuando se supone que los manantiales no podrían suministrar las cantidades suficientes. También pudiera ser que esta cisterna tuviera una disposición estratégica dentro de la muralla y por tanto accesible frente a las fuentes naturales que implicarían salir del recinto del poblado y acarrear el agua por las pendientes escarpadas.

En conjunto la situación expuesta expresa muy eficazmente la riqueza del entorno, la plena satisfacción de las necesidades en este aspecto.

\section{VEGETACION Y FAUNA}

Algunos análisis se han realizado sobre estas cuestiones en especial sobre fauna (Boessnek, 1969) (ARRIBAS y otros, 1974) para toda la cultura, apartado que reconstruiría el entorno mejor que ningún otro. Pero los yacimientos que estudiamos, si exceptuamos a Fuente Alamo, carecen de un estudio profundo. Si a ello añadimos las limitaciones de registro en función del método de excavación las aproximaciones son sólo eso, hipótesis parciales. Creemos sin embargo, que a partir de la vegetación actual y su fauna asociada también puede enriquecerse la visión.

La vegetación climax considerando los relictos actuales, estaría constituida por el llamado bosque mediterráneo claro de árboles pequeños y adaptados y con ramaje abundante asociados a maquias y espinares (RUBIO RECIO, 1988). En concreto las especies xerófilas y heliófilas representadas serían: Quercus ilex (encina), el palmito y la coscoja (Quercus coccifera), el acebuche (Olea europeae) y podría aparecer el Pinus halepensis o la vegetación ripícola. Como especies secundarias tendríamos el albardín, el esparto (Stipa tenacissima), la aulaga (Genista Scorpios), espinos o espárragos silvestres, tomillo (Thyrmus vulgaris), romero (Kosmarinus officinalis). La degradación sufrida ha dado lugar al predominio de estas últimas especies apareciendo además en zonas más bajas y secas el arto o azufaifo tunecino, la Callitsis articulata (en las Sierras de Almagro o Almagrera) o los salicores (DÍAZ ALVAREZ, 1981, 222 y ss.).

Como fauna potencial tendríamos pues especies de bosques como el ciervo, uro, jabalí, lince, erizo, lirón, zorro, gato montés, lobo, conejo, y en los espacios abiertos liebre, sisón, ratón de campo, asno salvaje. Entre las aves podríamos encontrar el Milano real, gavilán, la paloma, tórtola común, buho real, urraca, cuervo, avutarda.

Como decíamos la presencia en el entorno no implica explotación antrópica, en este sentido, frente a este potencial cinegético los restos recuperados en los yacimientos son escasamente representativos, además de haber sido recogidos muchos de ellos entre los restos funerarios y como ajuar. Esto contrasta con las afirmaciones generales que atribuyen una proporción del $80 \%$ y $20 \%$ a la fauna doméstica y a la fauna salvaje respectivamente (PELLICER CATALÁn, 1986) a partir de los datos obtenidos en determinados yacimientos como el Cerro de la Virgen de Orce. Para los yacimientos que estudiamos no tenemos cantidades porcentuales, pero las relaciones se pueden establecer mediante comparación relativa. Los registros exis- 
tentes, publicados por sus excavadores y vueltos a reseñar por ARRIBAS (1968) y NAVARRO MEDEROS (1983), son los siguientes:

\begin{tabular}{|l|l|l|l|}
\hline LUGARICO VIEJO & FUENTE VERMEJA & ARGAR & FUENTE ALAMO \\
\hline $\begin{array}{l}\text { Colmillo jabalí } \\
\text { Ciervo (asta) } \\
\text { Corzo }\end{array}$ & & Jabalí & Jabalí \\
& & & Ciervo \\
& & Corzo \\
Conus horadado & Pectunculus & Vérzebras pez & \\
& & Conus & \\
& & Dentallium sp. & Conchas de \\
& Glicymeris & moluscos \\
& Cardiumos & \\
& & Múrex & \\
& & Cipreas & \\
\hline
\end{tabular}

La aparición del jabalí que habita tanto los bosques mixtos de caducifolios, cerca de charcas, lagunas y pastos como zonas de matorral y monte bajo; del ciervo que se desarrolla en bosques alternantes con espacios abiertos, o del corzo con hábitat desde la llanura a la alta montaña en bosques con denso monte bajo combinado con zonas descubiertas húmedas, así como la presencia de la liebre, en terrenos llanos y bosques de caducifolios especialmente, aunque también en eriales y en zonas arenosas demuestra en conjunto la existencia de mayor humedad en la zona que la que puedan proporcionar las precipitaciones actuales, lo cual corrobora las afirmaciones que hemos realizado a propósito. Sería definitoria la aparición del corzo y no la presencia del lince típico del bosque mediterráneo, aunque también supondría la aparición de claros y asociaciones de matorral extenso.

Podríamos aventurarnos en la hipótesis de una mayor humedad de Fuente Alamo y Lugarico Viejo donde aparece el Corzo frente al Argar donde no está presente (lo cual contrasta con la aparición de lino que requiere gran humedad, aun cuando no sabemos del cultivo en las proximidades del yacimiento) pero en el cual si aparece la liebre ligada a una mayor aridez. Todo ello podría explicarse por las mayores precipitaciones recogidas en los citados yacimientos en función de la presencia de la Sierra de Almagro y Sierra Lisbona. Situación que todavía queda reflejado en la actualidad en la disposición espacial de las ramblas.

Desconocemos, sin embargo, los medios de explotación, tan sólo escasamente representados a través de los brazales de arquero que se citan para Fuente Vermeja o las puntas de hueso presentes en Fuente Alamo y Argar, a las que podemos añadir las puntas de flecha de este último yacimiento. Podrían haberse utilizado trampas de materia orgánica, perecederas por tanto.

En definitiva, la caza ante la escasez de medios materiales presentes sería llevada a cabo de forma esporádica o podría haber sido oportunista, aún cuando sería necesario el concurso de un grupo de personas para abatir por ejemplo al jabalí o al ciervo. 
Podríamos también preguntarnos por las necesidades a cubrir por las especies presentes, así como la proporción entre fauna doméstica y salvaje. La aportación energética para el consumo humano parece ser la razón principal salvo la utilización por su piel, por ejemplo del ciervo y para cuyo tratamiento no quedan evidencias materiales.

Aún así, esta fauna salvaje es la única que se cita para Lugarico Viejo y Fuente Vermeja. Para el Argar tanto fauna doméstica como salvaje están escasamente explícitas. Fuente Alamo cuenta por su parte con una mayor importancia relativa de animales domésticos, y en relación con ello está la potente industria osea aun cuando no se haya especificado si ésta corresponde a especies domésticas o salvajes (SCHUBART Y ARTEAGA, 1978).

Por otro lado, la aparición de especies marinas tendría que ser explicada en relación con el comercio puesto que la escasez de representación de los mismos no implica un consumo alimentario apareciendo además en los casos reseñados en las necrópolis y como objeto de ajuar. No obstante, no puede descartarse la expedición ocasional a la costa relativamente próxima.

La aparición de vértebras de pez en el Argar podría explicarse por la proximidad del Antas, aunque dudamos de su explotación como recurso alimentario por su nula representatividad así como de los medios necesarios para llevarla a cabo (tan sólo unos posibles anzuelos destacan sus excavadores).

Destaca la no explotación de ningún tipo de ave a pesar de las posibilidades del medio. El pico de ave que aparece en el Argar no significa en ningún caso su aprovechamiento.

Capítulo reseñable también y ampliamante representado y diversificado, aunque no siempre resaltado, es el de los recursos forestales. Se utilizaron postes de madera existentes en los restos de viviendas de Fuente Alamo, Lugarico Viejo y Fuente Vermeja, aunque no en el Argar donde se utilizan únicamente cañas en los tejados (igual que en Fuente Vermeja y Fuente Alamo). La madera pudo también ser utilizada como fuente de energía para la producción metalúrgica (carbón vegetal en Fuente Alamo y el Argar), sin embargo no hay constancia de la existencia de los instrumentos necesarios para su explotación y transformación, de no ser que consideremos que en el primer proceso están implicadas las azuelas que aparecen en el Argar o en Fuente Alamo o las escasas hachas metálicas de este último yacimiento y que podrían haber sido utilizadas como instrumento de peso para el abatimiento de los árboles.

Instrumentos utilizados para la transformación podrían haber sido las piezas de hoz presentes en todos los yacimientos estudiados, los objetos de hueso (puntas, punzones azagayas) existentes especialmente en Fuente Alamo y el Argar. O las sierras de pedernal del Argar (aunque localizados en la necrópolis).

El medio vegetal fue aprovechado también para la realización de tejidos y cestería. Así, verbigracia, los tejidos de lino en el Argar con los correspondientes instrumentos de transformación (pesas de telar). Esparto trenzado encontramos en Fuente Vermeja y Lugarico Viejo y en el mismo Argar. Utilizado en el primer yacimiento como tapa de una vasija no excluye otras utilizaciones (como contenedores en la recolección por ejemplo). Además la presencia de pesas de telar en todos los yacimientos y de husos en Fuente Alamo no supone la exclusividad del tratamiento de materias primas animales. 
Por último y en relación con la explotación-recolección hay que destacar la aparición de bellotas, hojas de árboles, flores y frutos en Lugarico Viejo que se citan de manera anecdótica pero que forman parte de la diversificación económica. Las bellotas podrían haberse transformado en harina o consumidas tal y como se presentan (suponiendo su utilización para el consumo humano). Las flores podrían cumplir una función ornamental pero como aprovechamiento derivado tendríamos la apicultura.

\section{EDAFOLOGIA, CULTIVOS Y GANADERIA}

Entramos en este momento en un asunto que merece especial atención por constituir uno de los principales recursos de subsistencia. La importancia o la ausencia de determinados métodos de explotación se ha considerado desde el punto de vista cualitativo y cuantitativo. Sin embargo las reconstrucciones efectuadas (LULL, 1983; GILMAN YTHORNES, 1985) no incluyen todas las variables que entran en juego. Sólo una descripción de los tipos de suelos existentes permitiría una valoración concluyente por la abrumadora expresividad de los datos. Verbigracia, los principales tipos de suelos según DíAZ ALVAREZ (1981) son:

- «Suelos de vega» cuaternarios y en las cuencas aunque penetran en los terrenos adyacentes.

- Suelos grises subdesérticos en la zona localizada al Este de los yacimientos estudiados, con límite septentrional en la desembocadura del Almanzora. Pobres en general salvo sobre zonas margosas y topografía suave.

- Suelos pardo-calizos asociados a litosuelos que predominan en la margen izquierda del Almanzora.

- Vertisuelos, en el término de Cuevas de Almanzora, con gran capacidad de agua y ricos en nutrientes.

Como destaca el «Catálogo de Suelos de Andalucía» (1984), son predominantes en la zona del Bajo Almanzora (en la que se incluye la Cuenca del Antas) los suelos pardo-calizos con buenas posibilidades agrícolas dependientes de la variable climática, siendo los más fértiles aquellos que se desarrollan sobre topografías y rocas suaves. Retienen bien la humedad y facilitan el enraizamiento de las plantas.

A partir de la cartografía existente (Mapa de Cultivos y aprovechamientos de la Provincia de Almería, 1982) hemos podido precisar que Lugarico Viejo, Fuente Vermeja y el Argar aparecen en zonas de inceptisoles (xerochrepts y calcixrochrepts), esto es pardo-calizos, limitando con Aridisoles, siendo estos últimos difíciles de explotar debido a la presencia de materiales calizos y de baja fertilidad. Por su parte, Fuente Alamo presenta las mismas características aun cuando limite también con los llamados suelos de vega (entisoles, Quartzipsamments) con permeabilidad y aireación buenas que redundan en una mayor fertilidad. Existirá pues una ventaja relativa para el aprovechamiento agrícola en este último yacimiento con respecto a los restantes, cuestión que vamos a discutir teniendo en cuenta otras variables tales como climatología, pendientes y escabrosidad. 
Como vemos, este sencillo análisis muestra el alto potencial agrícola en general y establece las matizaciones necesarias. Las valoraciones, sin embargo, se han cometido también intentando la interpretación a partir de los datos actuales (GILMAN Y THORNES, 1985). Se pueden anteponer ante este tipo de tratamiento numerosas críticas en función de la degradación antrópica que suponemos. De cualquier forma no lo descartaremos en tanto la situación presente implica en el caso de los terrenos de monte que estas áreas tuvieron la misma dedicación cuando se ocuparon los yacimientos, aunque su extensión fuese mayor. De este modo y atendiendo al aprovechamiento actual de los terrenos recogido en el Mapa de Cultivos y Aprovechamientos y en el Mapa Topográfico Nacional y según las cifras recogidas por GILMAN $(1985,165)$ podemos describir la situación para los distintos yacimientos de la siguiente manera:

El Argar: Actualmente en terreno inculto, domina el monte bajo en el NW., de igual manera en el NE. en la máxima distancia, mientras que en las proximidades tenemos frutales y huerta a lo largo del río así como espacio dedicado a secano y terrenos incultos. En el SW. alterna el monte bajo con los espacios incultos, mientras que en el SE. encontramos huertas abundantes a lo largo del río con presencia de frutales.

Evaluando las cifras porcentuales de hectáreas, secano y monte dominan en los primeros doce minutos con presencia de regadío relativa. Desde aquí hasta el radio de los 30 minutos aumenta el secano disminuyendo el monte y el regadío, a continuación monte y secano vuelven a equipararse, el regadío no aparece presente.

Lugarico Viejo y Fuente Vermeja: Considerados conjuntamente domina el monte bajo al Norte pasando hacia el Oeste a Monte Alto con Sierra Lisbona. En el SW. prosiguen estas características excepto para la zona regada por el Jauro con presencia de huertas y claros. En el SE. dominan los llanos salpicados por monte bajo en las mayores alturas apareciendo también eriales y olivares.

Para Lugarico Viejo tenemos un dominio del monte en los primeros doce minutos a los que sigue en importancia el regadío, mientras que esta dedicación disminuye en favor del secano desde los doce a los 30 minutos. El monte disminuye también progresivamente hasta una hora mientras que el secano aumenta.

En Fuente Vermeja, por el contrario, existe una mayor proporción de terrenos dedicados a secano en los primeros 12 minutos con presencia también del regadío, actividades que disminuyen entre los 12 y 30 minutos en favor del monte. Monte y secano se equiparan entre 30 ' y una hora. Ambos yacimientos se localizan actualmente en terrenos ocupados por el monte bajo.

Fuente Alamo: El monte bajo domina al Sur del yacimiento, mientras que el monte alto lo hace al NE. En el E. y NW. principalmente se desarrollan eriales y pastos. Cultivos agrícolas de secano en torno a las ramblas y huerta a lo largo del Almanzora.

Predomina de manera absoluta el monte en los primeros 12 minutos el cual disminuye a partir de aquí en favor del secano. Monte y secano descienden en porcentaje entre 30' y una hora apareciendo el regadío en esta zona. Igualmente el yacimiento se encuentra enclavado en un paraje dominado por el monte bajo. 
Las proporciones actuales (sin tener en cuenta el terreno ocupado por aterrazamientos y boqueras), para los diferentes yacimientos, que hemos elaborado a partir de las cifras totales y parciales de GILMAN que hemos mencionado, son en el radio establecido de los primeros $12^{\prime}$ las siguientes:

TABLA 1

\begin{tabular}{|c|c|c|c|c|}
\hline & $\begin{array}{c}\text { FUENTE } \\
\text { ALAMO }\end{array}$ & $\begin{array}{c}\text { FUENTE } \\
\text { VERMEJA }\end{array}$ & $\begin{array}{c}\text { LUGARICO } \\
\text { VIEJO }\end{array}$ & ARGAR \\
\cline { 2 - 5 } Monte $\ldots \ldots \ldots \ldots \ldots$ & $92 \%$ & $35,4 \%$ & $79,4 \%$ & $36,1 \%$ \\
Secano $\ldots \ldots \ldots \ldots \ldots$ & $4 \%$ & $56,8 \%$ & $5,9 \%$ & $39 \%$ \\
Regadio $\ldots \ldots \ldots \ldots$ & $3 \%$ & $7,72 \%$ & $14,5 \%$ & $12,26 \%$ \\
\hline
\end{tabular}

En el radio teórico entre 12' y 30':

\begin{tabular}{|c|c|c|c|c|}
\hline & $\begin{array}{c}\text { FUENTE } \\
\text { ALAMO }\end{array}$ & $\begin{array}{c}\text { FUENTE } \\
\text { VERMEJA }\end{array}$ & $\begin{array}{c}\text { LUGARICO } \\
\text { VIEJO }\end{array}$ & ARGAR \\
\cline { 2 - 5 } Monte $\ldots \ldots \ldots \ldots \ldots$ & $74,4 \%$ & $59,75 \%$ & $70,7 \%$ & $24,15 \%$ \\
Secano $\ldots \ldots \ldots \ldots \ldots$ & $22,9 \%$ & $34,75 \%$ & $24,1 \%$ & $62,8 \%$ \\
Regadio $\ldots \ldots \ldots \ldots \ldots$ & $0 \%$ & $5,3 \%$ & $4,41 \%$ & $3,7 \%$ \\
\hline
\end{tabular}

En el espacio comprendido entre $30^{\prime}$ y 1 hora:

\begin{tabular}{|c|c|c|c|c|}
\hline & $\begin{array}{c}\text { FUENTE } \\
\text { ALAMO }\end{array}$ & $\begin{array}{c}\text { FUENTE } \\
\text { VERMEJA }\end{array}$ & $\begin{array}{c}\text { LUGARICO } \\
\text { VIEJO }\end{array}$ & ARGAR \\
\cline { 2 - 5 } Monte $\ldots \ldots \ldots \ldots \ldots$ & $64,2 \%$ & $41,2 \%$ & $53,2 \%$ & $40,3 \%$ \\
Secano $\ldots \ldots \ldots \ldots \ldots \ldots$ & $14,7 \%$ & $46,6 \%$ & $34 \%$ & $40 \%$ \\
Regadí $\ldots \ldots \ldots \ldots \ldots$ & $8,1 \%$ & $1,96 \%$ & $3,08 \%$ & $1 \%$ \\
\hline
\end{tabular}

Si procedemos a una valoración, la explotación del suelo, en cuanto a hectáreas dedicadas al cultivo, alcanzaría su más alto grado en el Argar y Fuente Vermeja, mientras que Fuente Alamo seguido de Lugarico Viejo (los cuales podrían mostrar una mayor humedad) estarían en el extremo opuesto, subrayándose en todos ellos una dedicación casi exclusivamente cerealista.

Esto índices contrastan con la escabrosidad del terreno (GILMAN, 1985, 173 y ss.) (Mapa Geotécnico General Almería Garrucha), precisamente se aprovechó menos el suelo en aquellos yacimientos en que era más fácil el cultivo. Fuente Alamo muestra menores irregularidades en el terreno circundante en todos los radios teóricos considerados, frente al Argar con las mayores dificultades. 
Otras variables que se podrían considerar para el aprovechamiento agrícola (con las matizaciones expuestas) serían las precipitaciones y temperaturas. Si recordamos los datos recogidos en el apartado de climatología podemos argüir que Fuente Alamo presenta mayores precipitaciones $(250 \mathrm{~mm}$.) que el resto de los yacimientos, a lo que hemos de unir una menor temperatura y por ello menor evaporación, lo cual supondría mayores ventajas relativas.

Estos son en definitiva los planteamientos desde los que se puede abordar el estudio de la actividad agraria.

A continuación podemos analizar los restos materiales y evidencias de esta explotación en los distintos yacimientos. Esta base nos permitirá integrar el panorama y matizar aspectos varios con los que ubicar cada proceso en su puesto correspondiente dentro de la estructura.

TABLA 2

ESPECIES PRESENTES:

\begin{tabular}{|c|c|c|c|c|}
\hline & $\begin{array}{l}\text { FUENTE } \\
\text { ALAMO }\end{array}$ & $\begin{array}{l}\text { LUGARICO } \\
\text { VIEJO }\end{array}$ & $\begin{array}{l}\text { FUENTE } \\
\text { VERMEJA }\end{array}$ & ARGAR \\
\hline Trigo $\ldots \ldots \ldots \ldots \ldots \ldots \ldots$ & \multirow{7}{*}{$\begin{array}{l}x \\
x\end{array}$} & $\mathbf{x}$ & \multirow{5}{*}{$\mathbf{x}$} & $\mathrm{x}$ \\
\hline Cebada $\ldots \ldots \ldots \ldots \ldots$ & & $\mathbf{x}$ & & $\mathbf{x}$ \\
\hline Guisantes $\ldots \ldots \ldots \ldots \ldots \ldots$ & & & & $\mathrm{x}$ \\
\hline Habas $\ldots \ldots \ldots \ldots \ldots \ldots$ & & $\mathbf{x}$ & & \\
\hline Higo $\ldots \ldots \ldots \ldots \ldots \ldots$ & & & & \\
\hline Olivo $\ldots \ldots \ldots \ldots \ldots \ldots$ & & $\mathrm{x}$ & $\mathrm{x}$ & $\mathrm{x}$ \\
\hline Sin especificar: & & & & \\
\hline Hortalizas $\ldots \ldots \ldots \ldots \ldots$ & $\mathbf{x}$ & & & $\mathbf{x}$ \\
\hline Leguminosas $\ldots \ldots \ldots \ldots \ldots$ & & $\mathrm{x}$ & & \\
\hline
\end{tabular}

TABLA 3

Medios de producción y almacenamiento:

\begin{tabular}{|c|c|c|c|c|}
\hline & $\begin{array}{c}\text { FUENTE } \\
\text { ALAMO }\end{array}$ & $\begin{array}{c}\text { LUGARICO } \\
\text { VIEJO }\end{array}$ & $\begin{array}{c}\text { FUENTE } \\
\text { VERMEJA }\end{array}$ & ARGAR \\
\hline Azuelas . . . . . . . & $\mathrm{x}$ & & & $\mathrm{x}$ \\
\hline Piezas de hoz $\ldots \ldots \ldots \ldots \ldots$ & $\mathrm{x}$ & $\mathbf{x}$ & $\mathrm{x}$ & $\mathbf{x}$ \\
\hline Molinos . . . . . . . . . . & $\mathrm{x}$ & $\mathrm{x}$ & $\mathbf{x}$ & $\mathbf{x}$ \\
\hline 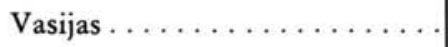 & $\mathbf{x}$ & $\mathrm{x}$ & $\mathbf{x}$ & $\mathrm{x}$ \\
\hline Estructuras $\ldots \ldots \ldots \ldots \ldots$ & $\mathbf{x}$ & & & \\
\hline
\end{tabular}

En cuanto a las especies documentadas destaca la ausencia de cereales en Fuente Alamo. Especie, por otro lado, presente de forma única en Fuente Vermeja. Por su parte el Argar y Lugarico Viejo presentan tanto especies de secano como hortalizas y leguminosas respecti- 
vamente lo cual posiblemente demuestra un aprovechamiento intensivo del terreno. De esta forma, y salvando las distancias, podríamos hipotéticamente comparar el terreno cuantitativo y cualitativamente explotados. Asi el Argar presenta el mayor número de hectáreas cultivadas en la actualidad junto con una dedicación intensiva de las mismas. Por su parte Fuente Vermeja, presenta un espacio considerable de hectáreas dedicadas exclusivamente a cereales. Lugarico Viejo aprovecha un espacio reducido de terreno disponible para el cultivo múltiple de leguminosas.

Fuente Alamo presenta de forma significativa el mínimo espacio dedicado a cultivos y además en éste desarrolla un cultivo dependiente del regadío.

El cuadro puede ser modificado si atendemos a los medios de producción y almacenamiento recuperados. Todo el proceso productivo está atestiguado materialmente para Fuente Alamo. Sólo en este yacimiento y en el Argar aparecen azuelas, posiblemente utilizadas en la preparación del terreno para la siembra por lo cual deberíamos poner en duda o relativizar la afirmación de LULL $(1983,235)$ acerca de que Fuente Alamo «no ofrece los medios de producción necesarios». En efecto en numerosas ocasiones se ha resaltado la escasa proporción de piezas de hoz en relación con otros yacimientos y con los molinos existentes (SCHUBART-ARTEAGA, 1983c, 60) hecho que bien pudiera deberse a una explotación cerealista realizada a cierta distancia del yacimiento (como se muestra en la actualidad), donde los terrenos podrían ser más productivos (con los llamados suelos de vega) y donde el aprovisionamiento de agua podría ser más fácil por la cercanía del Almanzora que indudablemente ocuparía una mayor superficie que en la actualidad. Ello coincide con la explotación actual del suelo, la mayor proporción de terreno dedicado a cereal se encuentra entre los 12 ' y los 30: No olvidemos tampoco la mayor productividad potencial de los suelos.

Requiere también una explicación la aparición de los llamados almacenes exclusivos de este yacimiento. Su presencia podría denotar la existencia de excedentes y puesto que no aparecen asociados individualmente a cada unidad de habitación podrían ser interpretados como contenedores de un bien comunitario aunque tampoco centralizado puesto que son cinco los detectados. Tampoco podemos establecer que fueran almacenes de grano. Esperamos que futuras excavaciones puedan aclarar su utilización con la cual reconstruir el sistema productivo y de distribución.

De otro lado, haciendo punto y aparte y aunque no quede todo dicho, pero si creemos que apuntado, podemos investigar a continuación el papel de la dedicación ganadera, imbricada en el modo de subsistencia agrícola. La problemática se plantea desde el punto en que son escasos los restos materiales y evidencias de su desarrollo en contraposición con los restos de fauna salvaje. Se ha señalado la presencia de Bos Taurus en el Argar (Navarro Mederos, 1983) donde también aparecen excrementos de cabra. Para Fuente Alamo se citan restos de ovicápridos en abundancia. Significativamente es en estos yacimientos donde se constata la industria ósea más desarrollada en cuanto a multiplicidad y variedad de utensilios. La sustentación de una cabaña ganadera estaría en función de la existencia de pastos abundantes, tanto más cuanto mayor sea el porte de ésta. No se ha puesto sin embargo en tela de juicio la distribución de éstos en cuya disquisición vamos a entrar a partir de las evidencias actuales y de las dedicaciones agrícolas que se establecen para el momento de ocupación. 
El Argar estaría favorecido en abundancia tanto por los barbechos como por las leguminosas (buenas forrajeras) sin necesidad de un desplazamiento costoso en tiempo, aunque estaría sujeto a una fuerte estacionalidad. No obstante, tenemos que apreciar la presencia de la canada Barbua que corre de W. a E. desde las lomas del Perro hasta el río y que queda incluida dentro del radio teórico de los 30 . Potencialmente podrían aprovecharse los pastos a los que conduce, pero no sabemos si fue o no utilizada esta vía. De cualquier forma la escasa representatividad de los animales domésticos hace considerar con reservas que esta actividad estuviese desarrollada.

En Fuente Alamo la abundancia estaría mermada hipotéticamente en función del escaso terreno ganado al bosque, pero tampoco es necesario recurrir a la tesis (LULL, 1983, 236) que sostiene una agricultura con barbecho largo con la cual asegurar el sustento continuado de la cabaña ganadera. Por el contrario, al NW. y W. del yacimiento corre una cabaña aprovechando la rambla de Gomara que se dirige, desde la zona de la Rellena en la Sierra de Almagro, al río en dirección norte-sur. Posiblemente se encontraría en esta zona, actualmente dedicada a erial y pastos (curiosamente una corona circular alrededor de la sierra de Almagro), el abastecimiento necesario para lo que se supone una importante cabaña ganadera en función de los restos encontrados. Podría suponerse un desplazamiento de mayor alcance en este pie de monte cercano a Fuente Alamo en contraposición al Argar (donde la aparición de excrementos podría tomarse por una mayor estabilidad del ganado).

Cabría preguntarse también por la ausencia de restos óseos animales (domésticos) en Lugarico Viejo y Fuente Vermeja. El mismo Lugarico Viejo podría haber aprovechado los posibles pastos de las Lomas del Perro, mientras que Fuente Vermeja lo haría con los barbechos de lo que supone una agricultura cerealista extensiva, o los pastos de Sierra Lisbona.

Quedan pues en entredicho o necesitadas de una mayor elaboración las conclusiones respecto a la importancia de la dedicación ganadera en tanto los restos de ésta y los de fauna salvaje explotada no parecen cubrir las necesarias aportaciones cárnicas.

\section{RECURSOS MINEROS Y METALURGIA}

En otro orden de cosas podemos describir de forma esquemática las principales afloraciones (Mapa Metalogenético de Almería; DíAz ALVAREZ, 1981, 1984) que pudieron ser explotadas dada la tecnología y necesidades existentes en los yacimientos que tratamos como marco previo para establecer en sus justos términos la sobrevaloración de esta actividad en la historiografía, que si bien es definitoria no se explica por sí misma, sino que más bien es imprescindible el análisis de las bases sobre las que se sustenta, para comprenderla.

Comenzando la relación por el Sur encontramos, plata, plomo y zinc al sur de la Sierra Cabrera, aun cuando su explotación podría ser dificultada por la distancia respecto a la cuenca del Antas, a más de $9 \mathrm{Kms}$. respecto de ésta.

En la Sierra de Bédar más accesible (a no más de 5 ó $6 \mathrm{Kms}$. de Lugarico Viejo) para los citados asentamientos, encontramos cobre. En una situación septentrional, tenemos también cobre en la Sierra de Almagro, cobre que se menciona incluso nativo para Fuente Alamo. 
Se constatan también aluviones auríferos que procedentes de la Sierra de Filabres discurrirían a lo largo del Almanzora a unos pocos Kms. al NE. del Argar.

En el NE. de los yacimientos del Antas y al SE. de Fuente Alamo está localizada Sierra Almagrera, donde es posible la explotación de plata, cobre, plomo y sulfoarseniuros compuestos. Fuente Alamo y el Argar distan del corazón de esta sierra 10 y 12,5 Kms. respectivamente.

Por último, podemos citar, por su importancia y singularidad, la presencia de estaño en la proximidad a la costa al norte del término de Aguilas, a unos 25 kilómetros de Fuente Alamo.

Es indiscutible la proximidad de las fuentes a los yacimientos, pero la determinación de éstos por aquéllas es controvertida. Las interpretaciones en boga (LULL, 1983; SCHUBARTARTEAGA, 1983c) sostienen la existencia de asentamientos que se dedicarían a la explotación de esta oferta en puntos estratégicos. La extracción no cubriría sólo las necesidades propias, sino que estaría orientada a un intercambio en bruto con otros hábitats peor situados. La contrapartida sería el grano necesario para la subsistencia dado que se supone que los poblados mineros dada su ubicación no serían autosuficientes desde el punto de vista agrícola. Creemos sin embargo que esta afirmación debe discutirse ampliamente y replantearse sobre distintas bases, atendiendo además a la distinta dinámica temporal del mundo argárico y a variables como la del número de pobladores en cada asentamiento. Esto es, las últimas excavaciones en Fuente Alamo alteran en nuestra opinión las hipótesis emitidas. El cuadro definitivo respecto a la explotación de los recursos es el siguiente, para cada uno de los yacimientos, y teniendo en cuenta los diferentes procesos de la cadena productiva:

TABLA 4

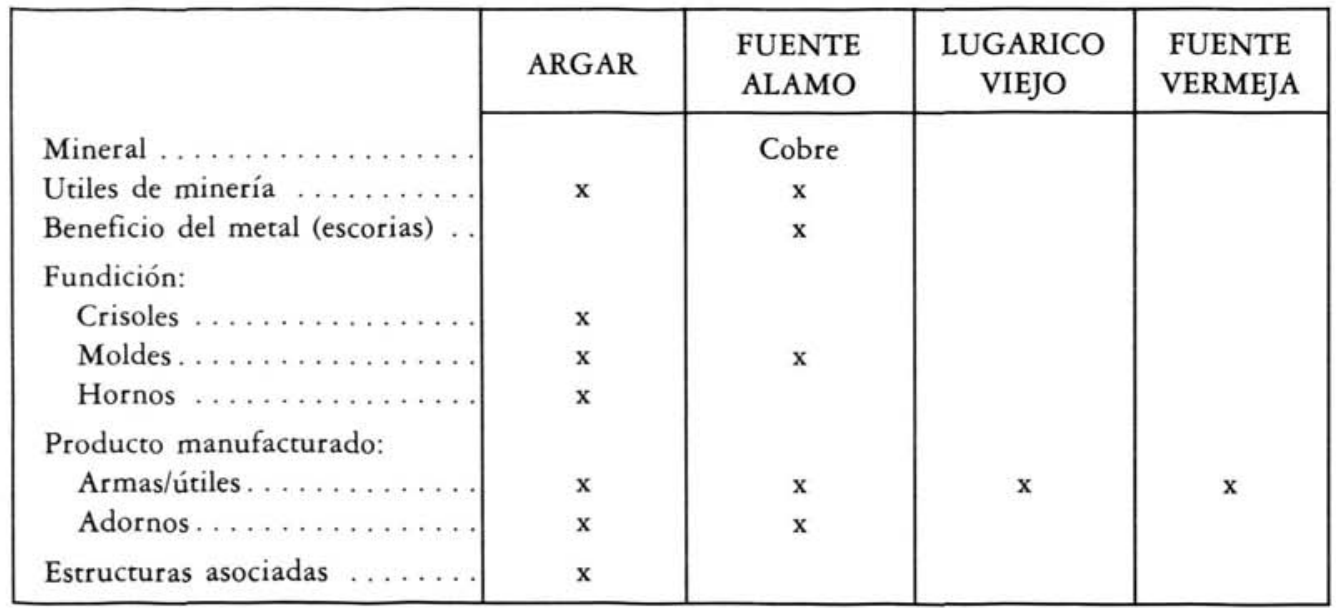

Destacan Fuente Vermeja y Lugarico Viejo por la ausencia de todo útil empleado para la explotación mineral en contrapartida con la existencia de productos finales aunque escasos (y en este caso tan solo útiles/armas y no adornos). Ello puede ser explicable si tenemos en cuenta las escasas tumbas estudiadas y las muestras de violación de las mismas así como 
la no especificación en el hábitat insuficientemente excavado. No obstante, hipotéticamente podemos advertir que las ausencias citadas son fruto de la no dedicación a esta actividad. Esto es, el intercambio habría llevado los productos manufacturados hasta los citados yacimientos a pesar de la posibilidad de aprovechamiento de la cercana Sierra de Bédar.

En el Argar se sostiene que el primer tratamiento del mineral, su beneficio, se podría realizar en otro lugar debido a la ausencia de escorias (LULL, 1983). Esta hipótesis se puede admitir teniendo en cuenta que si el proceso se hubiera realizado en el asentamiento, es lógico suponer se ubicase allí donde se realizaban el resto de las actividades metalúrgicas, las cuales aparecen concentradas en una estructura espacial conteniendo además un posible horno. Las razones podrían haber sido el transporte costoso del mineral en bruto, aún cuando el beneficio en un lugar distinto al asentamiento requiere una dedicación exclusiva por un grupo especializado. Tal vez el mineral se obtuviera a través del intercambio con otros asentamientos con un acceso más directo a los filones. Pero ahora bien, los mismos habitantes del Argar podrían haber realizado tal función, por ejemplo en la Sierra de Bédar o en la de Almagro. La existencia de útiles de minería apoya esta última hipótesis. De cualquier forma las dos posibilidades, intercambio o explotación directa, no son excluyentes, la primacía de una, de la otra o de ambas estaría en relación con la demanda y el coste-benéfico que no estamos en situación de enjuiciar.

En cuanto a Fuente Alamo, lugar para el que siempre se ha supuesto una localización preferente respecto a los recursos mineros, subrayándose incluso la facilidad de explotación de los mismos, debemos matizar una de las atribuciones expuestas en la tabla. Sus excavadores no resultan explícitos a la hora de mostrar la existencia o no de moldes de fundición, así expresan "no podemos hablar de la abundancia de moldes de fundición apropiados para la fabricación de tales piezas. Por el contrarioo hasta ahora faltan casi por completo" (SCHUBART-ARTEAGA, 1983c, 61). Es más se decantan por un traslado del mineral hacia otros asentamientos tras su extracción. Por una parte existen restos de escorias en el sitio, luego siquiera un autoabastecimiento podíamos asegurarlo. Por otro lado la ausencia de un número de moldes importante (a lo que podemos añadir la conocida ruptura de los mismos tras el proceso) podría estar ligada a un carácter fácilmente deleznable. Tal vez esta actividad en su proceso de transformación no sería obra de un grupo especializado de individuos y de ahí su no concentración en un espacio determinado. No obstante, la publicación de la memoria definitiva de las excavaciones llevadas a cabo así como futuros trabajos, podrán aclarar el significado del binomio presencia-ausencia.

Si estas afirmaciones las hemos realizado respecto de la explotación del cobre la de la plata resulta aún más explítica puesto que plantea el problema por ejemplo de cómo Fuente Alamo pudo trabajarla si no contaba con grano para el intercambio (materia de comercio según las distintas publicaciones como SCHUBART y ARTEAGA, 1983c). El panorama es pues más complejo y los productos intercambiados debieron ser diversos así como la multiplicidad de relaciones con ellos establecidos. La procedencia de la plata trabajada presente tanto en Fuente Alamo como en el Argar debió ser Sierra Almagrera ya que se presenta como la zona más cercana a los asentamientos para su explotación, no existiendo una primacía de ninguno de ellos en cuanto a accesibilidad, puesto que si bien en línea recta existe una venta- 
ja de Fuente Alamo, no así en lo que respecta a la topografía. La exclusividad de este metal en determinados ajuares de las respectivas necrópolis aboga bien por un intercambio selectivo (de prestigio), bien por una explotación ocasional directa al servicio de determinados intereses (con un mayor coste en función de la distancia).

Queda todavía pues mucho por decir sobre todo en lo que concierne a una generalización o no de la metalúrgia, a su alcance y función social, a la interdependencia de asentamientos atendiendo a ésta principalmente.

\section{ESTRATEGIA}

Es la estrategia la que en última instancia refleja la intencionalidad de los establecimientos. La disposición del territorio se ha establecido por ejemplo por LULL (1983) en términos de jerarquización espacial entre hábitats de los que se supone un mismo ecosistema, pero se ha atendido a la complementariedad de actividades económicas para definirla dejando a un lado la lectura del territorio visualmente controlado que contribuiría a especificar el por qué de un asentamiento y no de otro. Como método para llevarla a cabo exponemos un mapa en el que se recogen, en función de un círculo de $5 \mathrm{Kms}$. de radio sobre el terreno, tomando como centro cada uno de los asentamientos (camino teórico recorrido en una hora) las zonas visibles y de control. Hemos distinguido entre el territorio que se controla por estar a una menor altitud que el yacimiento (primera zona). Por otro lado destacamos el territorio visible por encima de la cota del asentamiento siempre que este terreno asciende y por tanto con control directo (segunda zona). Y por último aquella porción de terreno, cumbres principalmente, entrevistas, en función de la distancia, y las cuales no se pueden controlar por las vaguadas y descensos topográficos intermedios (tercera zona). Más allá de la línea que delimita esta última zona no se puede vislumbrar nada desde el asentamiento.

Así, analizando en primer lugar el Argar (Figura 3), el dominio en las cotas más bajas que el yacimiento, se centra en una franja en dirección Sur que se extiende algo por el SE. Supondría el control del curso del río y de su margen derecha hasta las primeras alineaciones montañosas. El territorio controlado visualmente aún por encima de la cota del yacimiento (segunda zona), considerando sólo el ascenso, se extiende en dirección Norte siguiendo la rambla de Cayete, hacia el NW en el recodo del Jauro y hacia el SE. hasta las Lomas del Perro. Las zonas entrevistas son las que resultan de las direcciones apuntadas por las mayores elevaciones, esto es, la Rambla de Cayete y los terrenos situados a izquierda y derecha, una pequeña franja al Este hasta Vera y por el W. hasta Fuente Vermeja (visible en la lejanía). Tenemos, pues, un mayor campo al S. y al W. mientras que los terrenos hacia el Almanzora apenas son vislumbrados en función de los diferentes cabezos previos al valle.

En relación con la estrategia del asentamiento podemos mencionar los datos existentes en torno a una muralla de piedras de las que se desconoce su posición-orientación. Conocemos que posee accesos al Sur y al Este. Puesto que al Oeste tenemos márgenes cortadas a pico la disposición no es casual. 


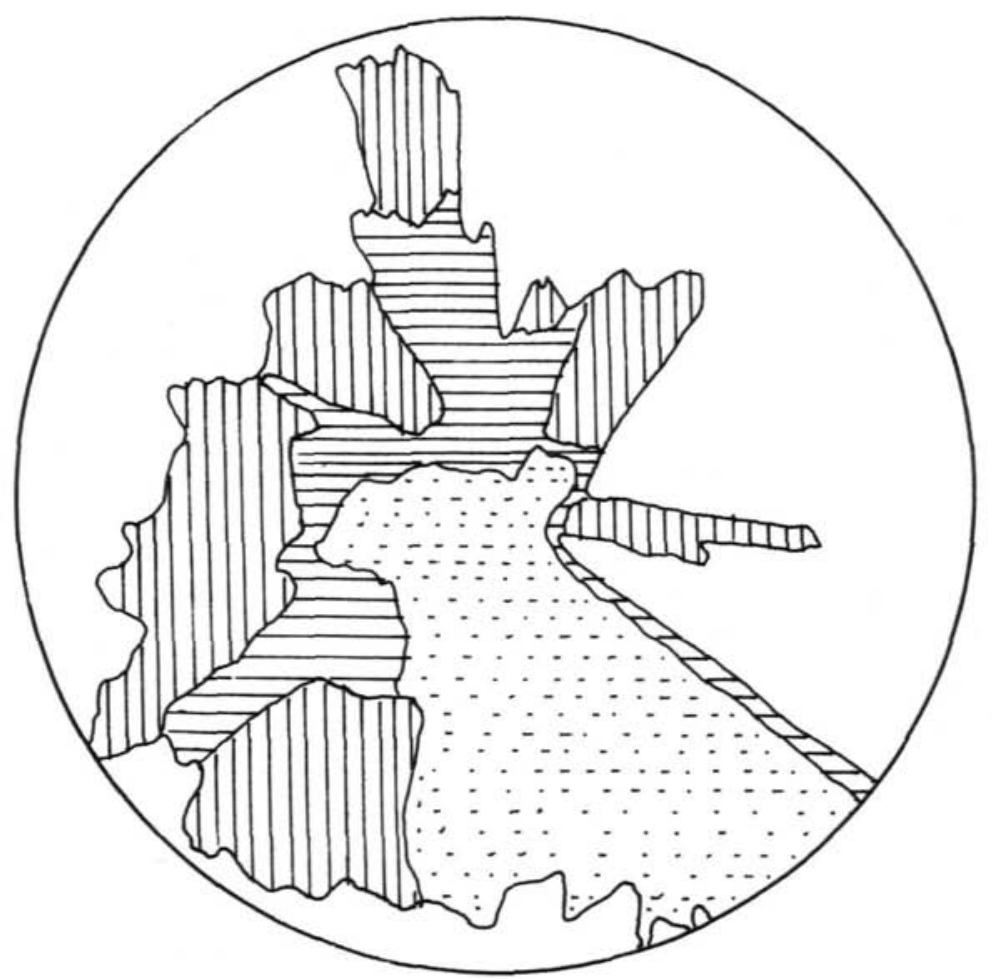

::-: ZOKA A MENOR ALTURA CONTROLADA

E ZONA A MAYOR ALTURA CONTROLADA

IIIII ZONA VISLUMBRADA NO CONTROLADA

$\square$ ZONA NO VISIBLE

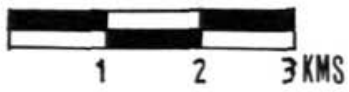

FIG. 3. - Visibilidad del Argar. 
De otro lado, las vías de comunicación actuales (Figura 4) se vertebran en dirección N.-S. al Este del yacimiento con la carretera Nacional 340 dirección Cádiz que a su paso por Vera origina numerosos ramales. También aparece una carretera local que a partir del Km. 199 de la anterior se dirige hacia Huercal-Overa atravesando Antas. Otro entramado de caminos se origina a raiz del río en una y otra vertiente al Oeste del yacimiento (en el recodo del Jauro-Antas). Con las debidas precauciones y sin deseo de hacer extrapolaciones podemos decir que la disposición de la carretera local que hemos citado coincide en su trazado con una zona controlada en su totalidad desde el yacimiento. Probablemente esta vía está asentada en un terrene de acceso natural de penetración que podría haber sido utilizado en el momento de ocupación del yacimiento.

Aún más este control del territorio se realiza efectivamente sobre zonas potenciales explotables desde el punto de vista agrícola al situarse a lo largo de la llanura aluvial. Dedicadas actualmente a huerta, cereales y olivar. El yacimiento controla también una zona de monte bajo al Sur de las Lomas del Perro y en la que queda comprendida la cañada Barbua.

Lugarico Viejo (Figura 5) domina una primera zona que coincide con la zona controlada por el Argar (visible desde el yacimiento) añadiendo además el espacio comprendido entre ambos asentamientos, controla incluso efectivamente la rambla de Cayete, al NE. Fuente Vermeja y al SW. el Jauro. Esto es, debido a su posición y mayor altura, es visible todo el río Jauro desde el punto en que deja de ser el Antas hasta las mayores alturas de las Lomas del Perro. La segunda zona de control efectivo establecido prolonga la anterior al N., S., y W. unos dos kilómetros y supone el dominio de los accesos a Sierra Lisbona y la margen izquierda del río hasta las primeras estribaciones de Sierra Filabres.

Por último, vislumbra una estrecha franja que se prolonga hacia el NE. del asentamiento en dirección a la rambla del Serrón y todo el cuadrante SW. hasta los inicios de la Sierra de Bédar en el límite teórico de los 5 kilómetros.

Debemos mencionar la existencia de una muralla con escalones, de planta circular y construida con cantos rodados de tamaño medio y pequeño y de disposición irregular con accesos orientados al SW. Es posible establecer una relación entre la orientación del acceso y la zona de peor accesibilidad debido a los escarpes rocosos (en contraposición al Argar). Las consideraciones defensivas no deben estar ausentes. Tal vez en su concepción estuviese presente la idea de una posible penetración por el valle con lo cual el poblado al no presentar accesos en esta vertiente Norte quedaba resguardado, siendo además una zona sobre la que ejerce un dominio efectivo. Esta hipótesis se contrapone con la presencia de viviendas al exterior de la muralla. Aunque debido al desconocimiento de sus relaciones cronológicas y orientación no procederemos a su interpretación.

Las comunicaciones actuales de mayor envergadura se establecen en el lado Este del yacimiento con la citada carretera local que comunica Antas con Huercal-Overa. Los mismos caminos en torno al río que mencionábamos entran en su ámbito. A ellos hay que añadir los que adoptando una disposición irregular parten desde las distintas elevaciones a SW. y NW. hacia esa zona (caminos carreteros).

De esta forma, existe un control de la zona situada al Este del yacimiento en la que se localiza la carretera local y sus múltiples ramificaciones. Queda al márgen la visibilidad de 


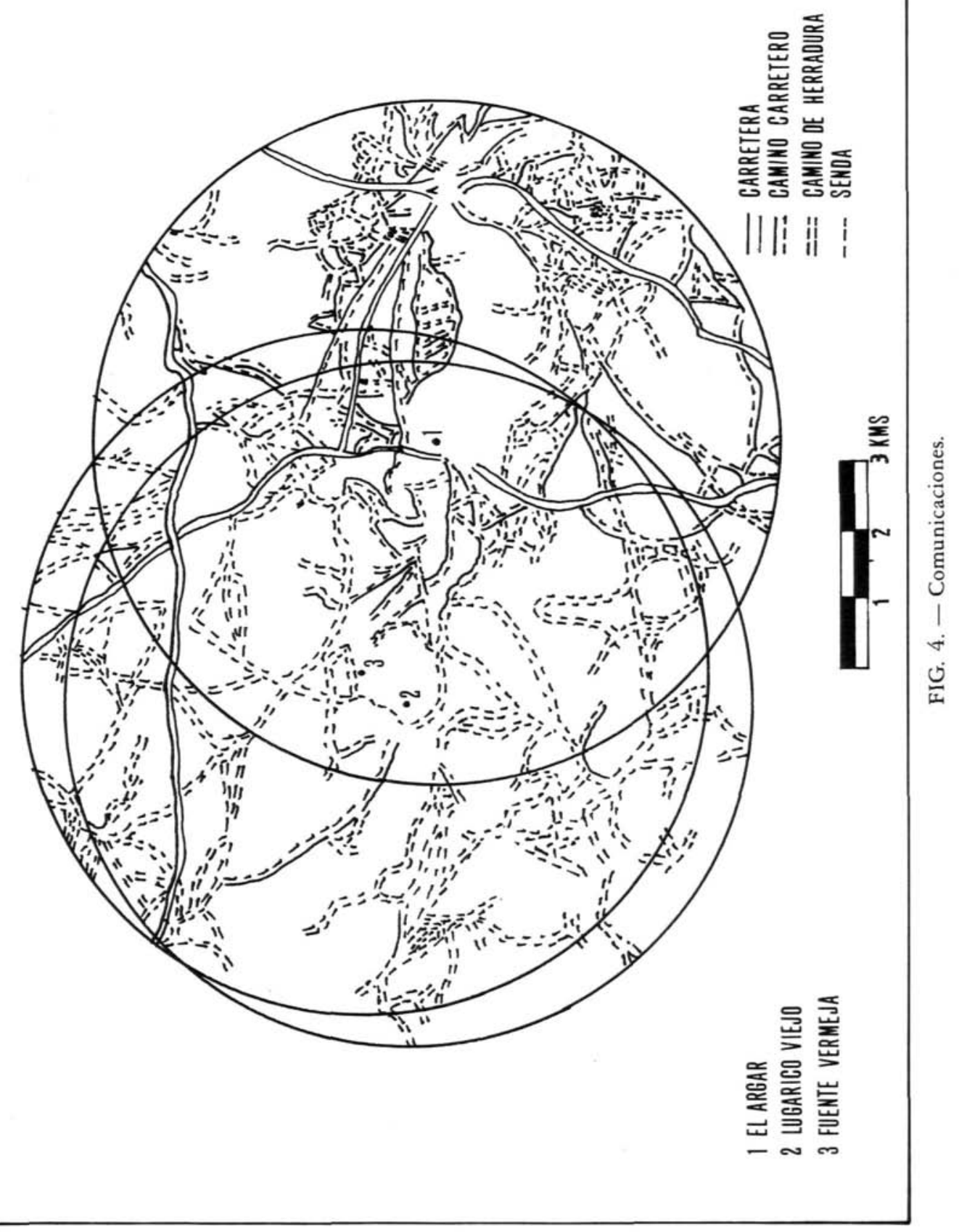




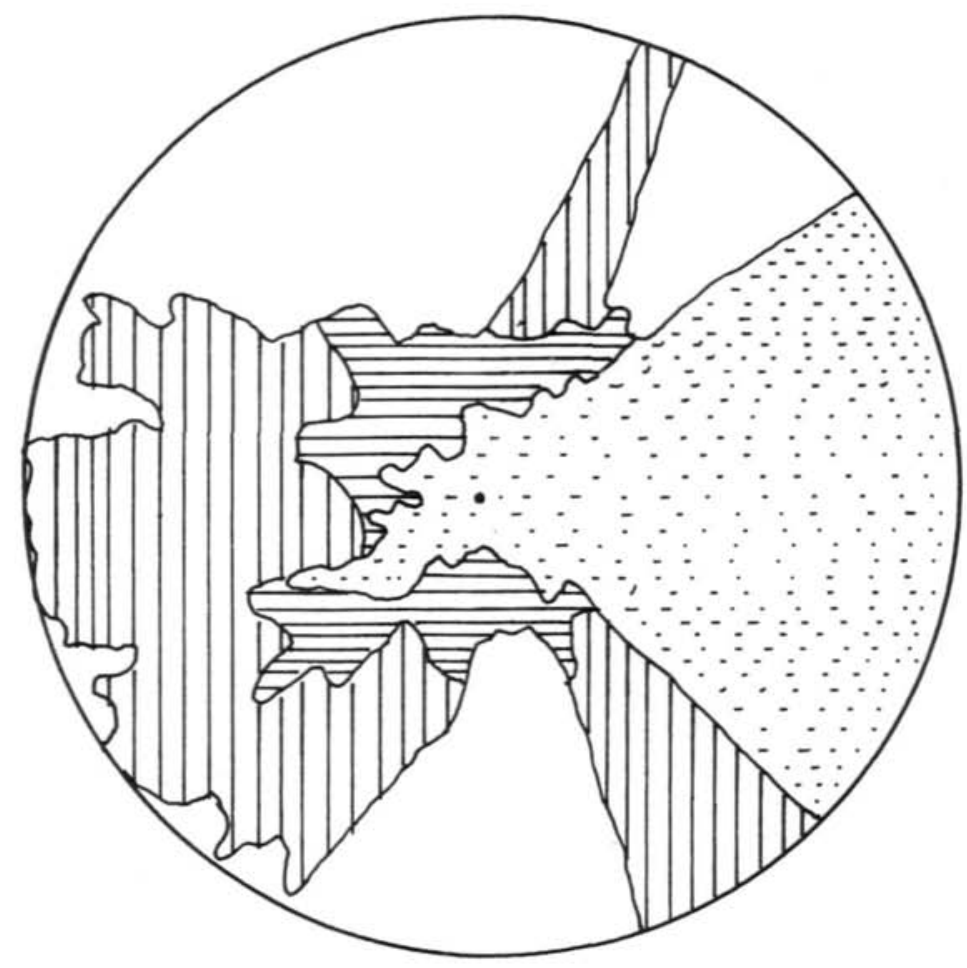

:::: ZONA A MENOR Altura CONTROLADA

E ZONA A MAYOR ALTURA CONTROLADA

पIII) ZONA VISLUMBRADA NO CONTROLADA

Z ZONA NO VISIBLE

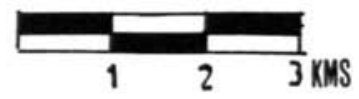

FIG. 5. - Visibilidad de Lugarico Viejo. 
la carretera que parte de Cuevas de Almanzora de disposición Este-W (al Norte de Sierra Lisbona) y que sigue la dirección de la rambla del Serrón.

Igualmente Lugarico Viejo controla tierras aprovechables desde el punto de vista agrícola de manera directa en el valle del río, mientras que en altura lo hace sobre terrenos de monte bajo (zonas de acceso desde el valle a las estribaciones montañosas respectivas), con una primacía de la primera estrategia cuantitativamente.

Por su parte Fuente Vermeja (Figura 6) supervisa en cotas inferiores, la misma zona al E, SE. del yacimiento que Lugarico Viejo. No obstante en Fuente Vermeja se reduce el campo de visión, y por tanto control efectivo, sobre la rambla de Cayete y la zona al Sur de Lugarico Viejo. En el caso de la segunda zona adopta también un control sobre un territorio análogo en disposición al que controla Lugarico Viejo, pero al Norte de Fuente Vermeja la presencia de una pequeña elevación dificulta el dominio efectivo sobre la zona amesetada previa a Sierra Lisbona.

Fuente Vermeja, a diferencia de Lugarico Viejo, vislumbra, aunque no controla de manera efectiva las Lomas del Perro en su totalidad a pesar de que no lo hace en la zona adyacente que corresponde al tramo medio de las ramblas que vierten al río. De esta forma los dos yacimientos se complementan para el dominio visual aunque a distancia de esta zona SE.

Las consideraciones en torno a las comunicaciones y aprovechamiento potencial de los recursos coinciden con las realizadas para Lugarico Viejo.

También Fuente Vermeja cuenta con una muralla cuya función es cuestionada al constituir un muro común a las casas del poblado (sin embargo hay que anotar su mayor espesor en comparación con las compartimentaciones internas). De cualquier forma podemos interpretar la orientación o accesos al poblado formen estos parte o no de una muralla. La entrada se realiza por el Este. La técnica es compleja en uno de los casos con una rampa y una puerta acodada lo que por sí mismo es significativo y más dado que al Este existe un abarrancamiento del terreno aunque en conjunto la zona es más accesible que las que aparecen cortadas a pico.

Es preciso citar también que aparece realizado un desmonte del terreno para buscar la horizontalidad de la ladera, en la que se ubica. Las zanjas practicadas sirvieron de paredes para las casas. Si atendemos además a la planta proporcionada por SIRET (1890, lám. 13) la muralla estaría orientada en el norte y noreste, lo cual coincide con la zona de menor control directo por parte del yacimiento.

Las consideraciones estratégicas de Fuente Alamo han sido puestas de relieve por sus escavadores quienes subrayan su control perfecto de la ruta del valle del Almanzora y la penetración en la Sierra de Almagro (SCHUBART-ARTEAGA, 1983a, 22 y ss). Espacialmente (Figura 7) el dominio del territorio situado a una cota inferior comprende toda la zona situada al Sur del yacimiento considerando los $5 \mathrm{Kms}$. teóricos. Hacia el Este domina incluso la zona meridional de la Sierra de Almagro. Esto es también todas las ramblas que en dirección N-S. descienden al Almanzora. El río mismo, y aunque fuera del marco teórico de trabajo que nos hemos propuesto, se divisaría al igual que el Argar. Aproximadamente el ángulo de control visual efectivo abarcaría hasta el punto de unión de las ramblas del Serrón y Cayete y por el SE. la misma desembocadura del Almanzora. Las estribaciones de Sierra Almagrera 


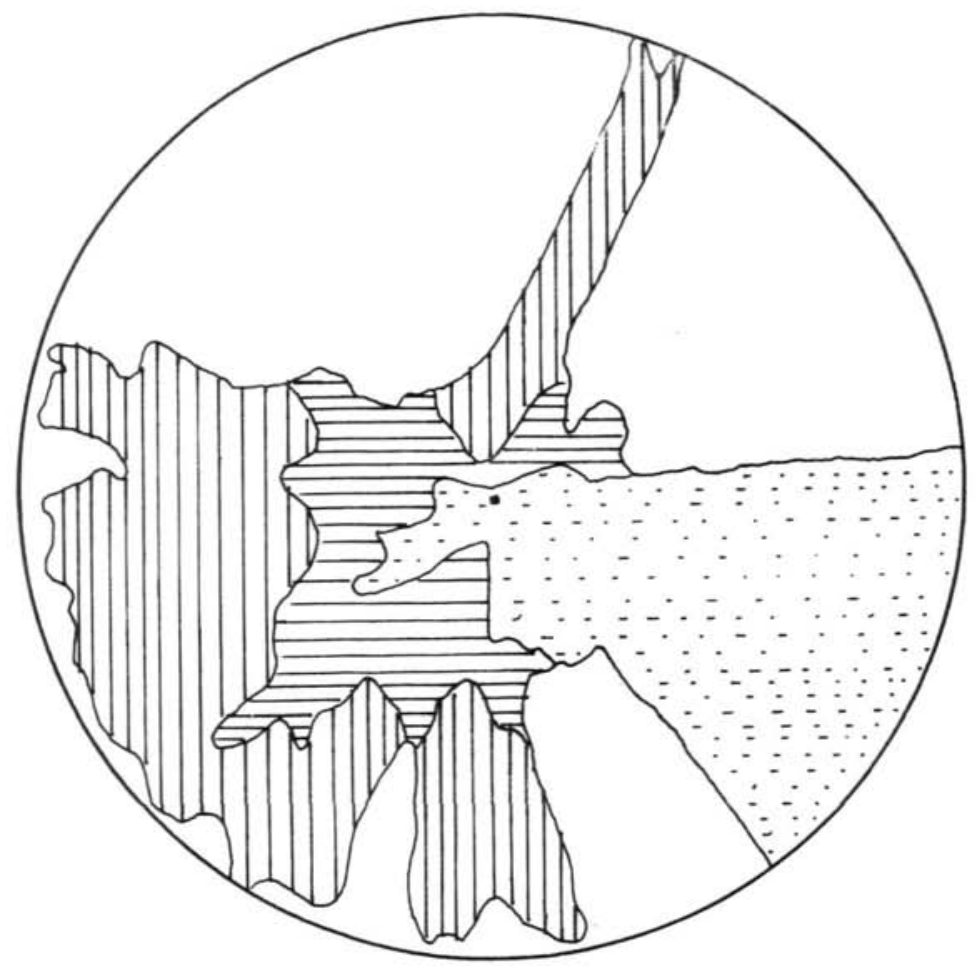

:::-: ZONA A MENOR ALTURA CONTROLADA

E ZONA A MAYOR ALTURA CONTROLADA

UIIII ZONA VISLUMBRADA NO CONTROLADA

$\square$ ZONA NO VISIBLE

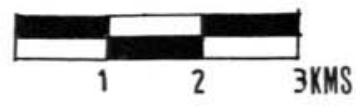

FIG. 6. - Visibilidad de Fuente Vermeja. 


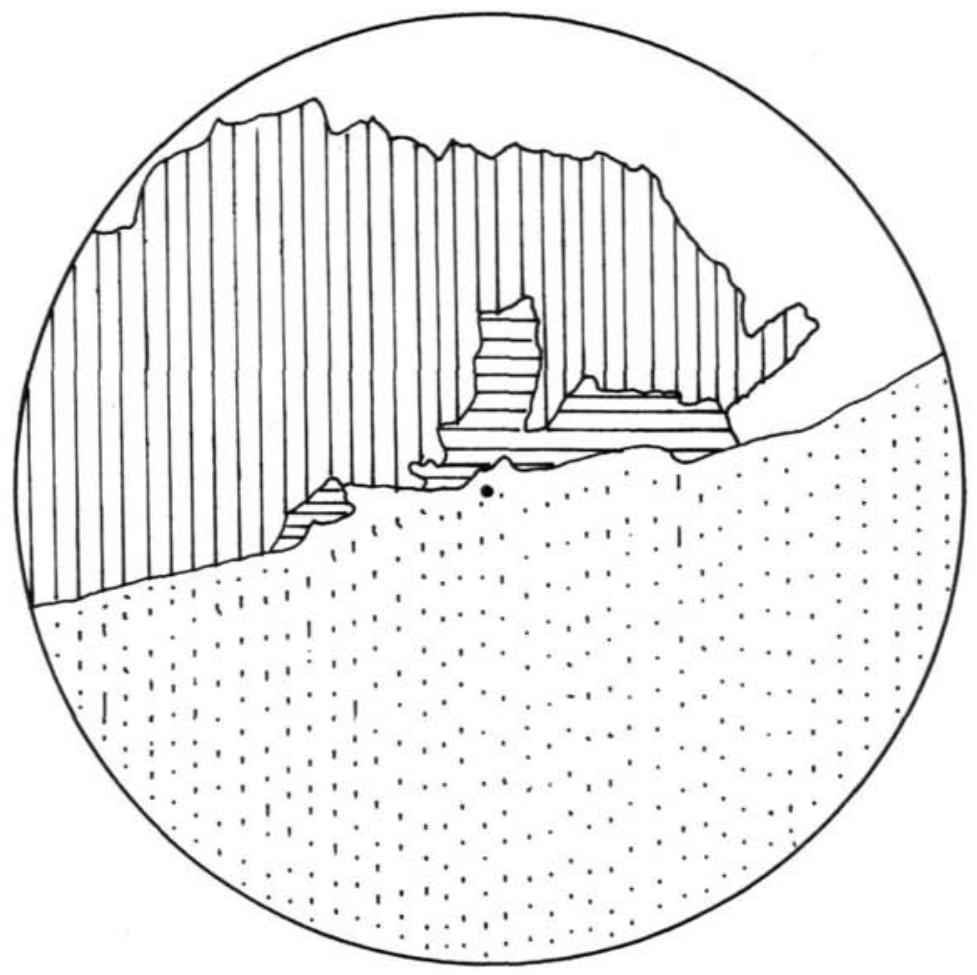

:::-2 ZONA A MENOR ALTURA CONTROLADA

E 2ONA A MAYOR ALTURA CONTROLADA

DIII ZONA VISLUMBradA NO CONTROLADA

$\square$ ZONA NO VISIBLE

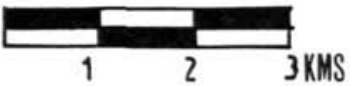

FIG. 7. - Visibilidad de Fuente Alamo. 
impedirían la visibilidad de la costa en este punto, aunque la línea de playa podría ser vista y controlada entre esta Sierra y la de los Pinos.

Por el contrario, por el Norte (NE. y NW.) el control efectivo es muy limitado, las elevaciones al Norte del yacimiento permiten la visibilidad hasta Cerro Pelado y Martín Pérez en altura detrás de las cuales se vislumbran las cimas pero no existe control real.

El control efectivo al Sur coincide con el de las zonas de mayor posibilidad de aprovechamiento agrícola en las llanuras del Almanzora en la actualidad dedicadas a un aprovechamiento intensivo hortícola, pero también supone dicho control, la posibilidad de aprovechamiento del monte bajo el SE. del yacimiento y por tanto sus recursos faunísticos.

Si ponemos en relación con este control visual la disposición de la red viaria actual (Figura 8) podemos ver que la concentración de comunicaciones se dispone en el territorio situado al sur del yacimiento en función desde luego de la presencia de Cuevas de Almanzora que determina una disposición radial. En cualquier caso y para evitar interpretaciones erróneas esta comparación establecida tiene el fin de subrayar la facilidad potencial del desarrollo de comunicaciones en esta zona sur sobre la que se ejerce un control de hecho desde Fuente Alamo.

También se mencionan algunos tramos de muralla en la zona Norte y Sur, pero no se da noticia de posibles accesos y de la extensión y planta de la misma, puesto que las excavaciones y memoria quedan por confirmarlo. Igualmente se procedió a la adaptación del terreno para habitación mediante una nivelación del mismo.

Realizado este esquema, las conclusiones respecto a una interrelación entre los asentamientos pueden establecerse hipotéticamente, aunque reservamos el juicio definitivo hasta contar con estudios complementarios a nivel regional y posiblemente interregional.

\section{CONCLUSIONES}

Llegados a este punto del discurso y una vez que creemos tratadas las distintas variables económicas (a excepción del comercio apuntado tan sólo en sus vías) y expuestas las argumentaciones que se extraen de la lectura de las diversas publicaciones, queremos recapitular de forma sintética las deducciones a las que hemos llegado en los distintos aspectos.

Se pueden resumir las características de los asentamientos estudiados en los siguientes puntos:

- Se consideró prioritaria la ubicación en una cota de mayor altura relativa con respecto al entorno ocupándose las cimas y laderas en el caso de Fuente Alamo y el Argar, aunque es imposible determinar si el asentamiento en una zona u otra fue contemporáneo o existe una prioridad en el tiempo de una respecto a otra. Lugarico Viejo ocupó sólo la cima y Fuente Vermeja se asentó exclusivamente en la ladera.

- Las construcciones se asientan en zonas niveladas en sentido horizontal bien naturalmente como en el Argar o en Lugarico Viejo, bien artificialmente mediante el desmonte del terreno como en Fuente Vermeja y en Fuente Alamo. En todos los casos se utilizaron materiales constructivos existentes en el entorno inmediato. 


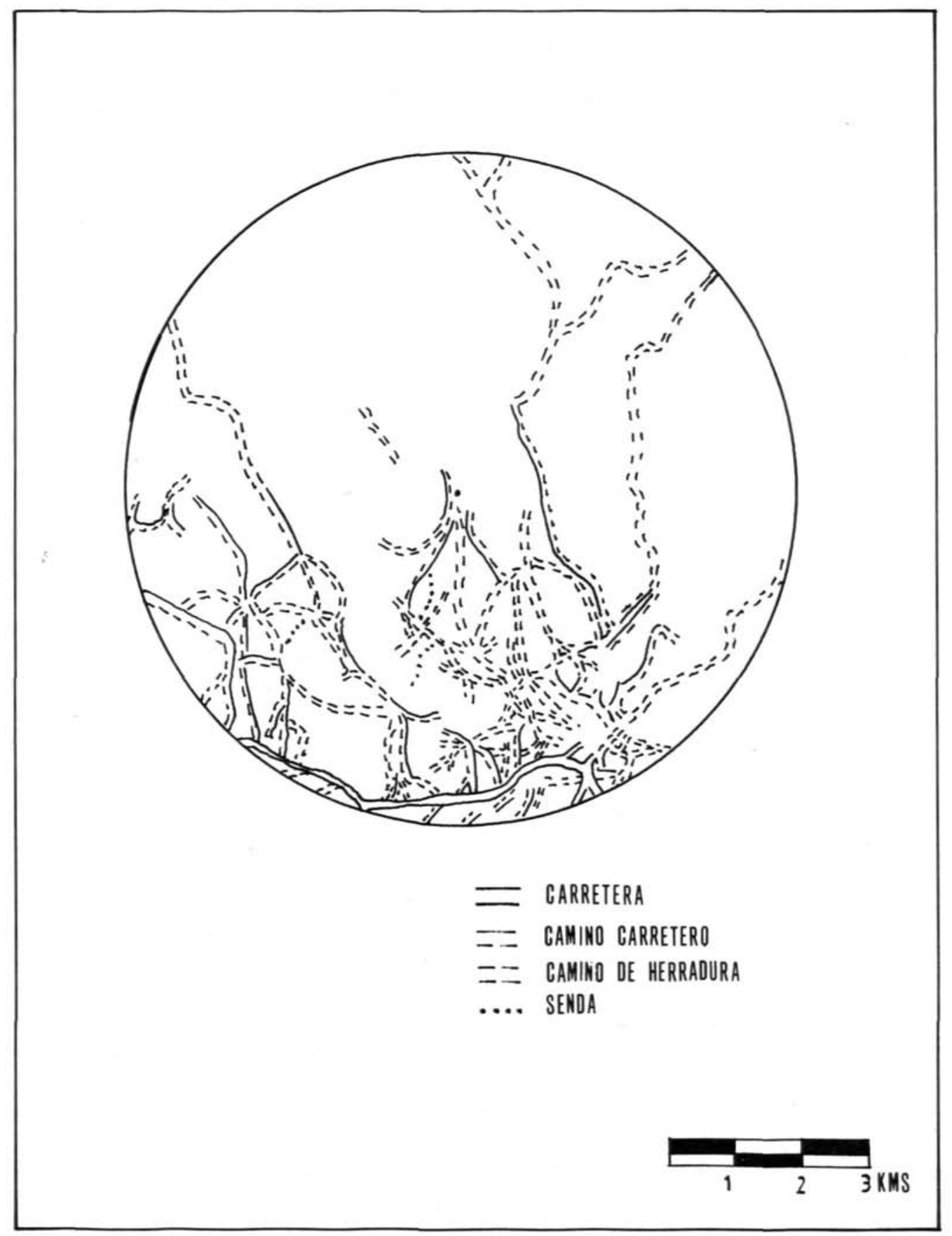

FIG. 8. - Vías de comunicación en Fuente Alamo. 
- El abastecimiento de agua está asegurado en todos los yacimientos. En primer lugar destaca la proximidad a los cursos de agua regulares como son el Jauro-Antas o el Almanzora. Tanto el Argar como Lugarico Viejo cuentan en sus proximidades con ramblas que suponen aportes irregulares de agua. Por su parte Fuente Vermeja y Fuente Alamo cuentan con un abastecimiento más constante con la presencia de fuentes naturales que dan nombre a los mismos.

- El bosque mediterráneo como unidad fitológica climax, junto con su asociación faunística aparece explotado en forma de materiales de construcción (madera) o utilizado como fuente de energía en la industria metalúrgica. También la explotación pone las bases para el desarrollo de labores de tejido y cestería presentes de forma efectiva en todo su proceso. Los frutos pudieron también extraerse como los de encina presentes en Lugarico Viejo.

Frente a este aprovechamiento diverso y múltiple representado en todos los yacimientos, destaca el escaso desarrollo de la actividad cinegética (no presente en Fuente Vermeja) tanto por la práctica inexistencia de medios para llevarla a cabo como por la escasez de especies presentes en los distintos hábitats. Unicamente podría matizar la situación la industria ósea de Fuente Alamo y el Argar, aunque es dudoso pensar en su origen en una fauna salvaje ya que no está explícito. En relación con las especies explotadas son estas de bosque como el ciervo jabalí o el corzo, es decir de gran porte (jactividad colectiva?). La liebre ligada también a espacios abiertos está presente en el Argar.

- En cuanto a la litología, geología y edafología existe una unidad en los asentamientos con matizaciones. Todos ellos están asentados sobre terrenos terciarios (con predominio de calizas) que aparecen cubiertos con aluviones cuaternarios. Fuente Alamo añade a los materiales comunes la presencia de basaltos.

Igualmente, frente a la presencia masiva de suelos pardo-calizos en Lugarico Viejo, Fuente Vermeja y el Argar, Fuente Alamo cuenta además con los llamados suelos de vega en sus proximidades. Esta característica junto con una menor escabrosidad en el entorno inmediato, mayores precipitaciones y menores temperaturas sitúan a este último yacimiento en un posición privilegiada potencialmente.

- El aprovechamiento agrícola se muestra como una actividad desarrollada en todos los asentamientos teniendo en cuenta las hectáreas dedicadas en la actualidad (especialmente en Fuente Vermeja y el Argar si es posible una extrapolación) y la presencia de los medios de producción necesarios en toda la cadena productiva incluyendo la transformación. Especies de secano y de regadío aparecen en Lugarico Viejo y el Argar. Fuente Vermeja se dedica sólo a los cereales y únicamente se dieron cultivos de regadío en Fuente Alamo, aunque en este último debió existir el cultivo del cereal en función de los instrumentos de producción existentes.

Esto es, no podemos afirmar un predominio de unas u otras especies. Es posible suponer el desarrollo de una agricultura intensiva en aquellos yacimientos con presencia de cultivos de regadío, pero ello puede obedecer también a una no especialización, o sea, a la diversificación dietética dado el alto potencial hidrológico ofrecido por el medio. No obstante, diversas hipótesis pueden mostrarse (que hemos apuntado en el desarrollo general) incluyendo la variable referida a hectáreas cultivadas, además de la dedicación de las mismas teniendo tam- 
bién presentes las estimaciones de la población que podría sustentarse en función del número de individuos hallados en las necrópolis.

- No existe explícitamente el mantenimiento de una cabaña ganadera si exceptuamos a Fuente Alamo. Los medios necesarios para su desarrollo están presentes en el entorno inmediato en forma de agua y pastos indistintamente para todos los asentamientos. Incluso la relación costo-beneficio sería más rentable para el resto de yacimientos (si tenemos en cuenta la distancia hasta la base de sustento) que para Fuente Alamo.

La presencia de instrumentos para llevar a cabo actividades textiles y la industria ósea (significativamente sólo desarrollada en el Argar y Fuente Alamo) nos revelan indirectamente que al menos aunque como actividad secundaria debió existir.

En cualquier caso sería necesario preguntarnos por el origen de la necesaria aportación proteínica cárnica dados los escasos restos tanto de fauna salvaje como doméstica (explicando la primacía de una u otra para cada uno de los casos).

- Existe una proximidad de los asentamientos a filones metaliferos explotables en las sierras de Almagro y de Bédar. El cobre presente en éstas fue extraído y manipulado directamente, tanto en el Argar como en Fuente Alamo. Existiría una ventaja de este último en relación a la mayor proximidad de la materia prima, siendo ésta además nativa, con lo que el beneficio sería más fácil y rentable. La manufactura del metal de cobre no se puede afirmar para Fuente Vermeja y Lugarico Viejo.

No podemos atestiguar sin embargo la extracción directa de la plata (aunque si del oro) de manera regular en función de la distancia a los filones de Sierra Almagrera tanto desde Fuente Alamo como desde el Argar. Abogaría también por ello la presencia diferencial, en los distintos enterramientos, de los objetos con ella elaborados.

La metalurgia de modo general, y en relación con la agricultura, posiblemente fue una actividad secundaria si nos atenemos a la presencia de productos elaborados tan sólo en los enterramientos y suponiendo que no muestran huellas de uso (según lo que es posible deducir de las publicaciones) que no se presentan pues como instrumentos de producción. La discusión está entonces abierta en torno a la interpretación de la metalúrgia según parámetros sociales, ya que creemos que las explicaciones dadas no son suficientes.

- Considerados los asentamientos a nivel espacial se deduce un control del territorio complementario entre ellos. De tal forma que superpuestos sus campos de visión ésta se ejerce para el territorio comprendido entre ellos si procedemos a unirlos mediante una línea.

Especialmente la zona de dominio efectivo se prolonga más allá de este marco en virtud de la visibilidad del Argar por el Sur-Sureste y principalmente por el más amplio control hacia el Sur de Fuente Alamo. Esto es, existe un dominio de las cuencas medias del JauroAntas y del Almanzora (precisamente en esta orientación se ejerce el mayor control efectivo del espacio).

La razón de esta disposición puede obedecer a la existencia en esta zona de los mejores suelos desde el punto de vista agrícola, pero también a un supuesto tráfico comercial en tanto las zonas controladas constituyen vías naturales de penetración.

Se buscó una posición estratégica, que hemos comentado. Se dotó a los poblados de sistemas defensivos artificiales que complementan las naturales e incluso complejas técnicas (es- 
pecialmente en Fuente Vermeja). Los accesos se articularon en las zonas más adecuadas excepto en Lugarico Viejo.

Creemos que son estas características generales de acuerdo con una nueva lectura de los asentamientos y su indudable interdependencia con el entorno, las que definen la cultura argárica a niveles económicos (y para la provincia de Almería). El estudio del resto de materiales quedaría por hacer con el fin de mostrar las relaciones interasentamientos para establecer posibles conjuntos o redes de influencia intercambio que conllevarían un replanteamiento de las distinciones establecidas hasta el momento.

Las actividades desarrolladas explicarían también determinados aspectos de organización social que deben hacerse más explícitos. A ello contribuiría el estudio de los asentamientos mostrando el funcionamiento estructural de esta sociedad, no limitándose a describir sus características.

Finalmente sería necesario completar todo ello con el estudio de la dinámica del mundo argárico en su secuencia temporal, esto es, explicar las cronologías atribuidas en su conjunto mostrando el peculiar desarrollo en cada momento, no sólo en función de los cambios materiales, sino de los cambios producidos en la estructura económica (que suponemos no coincidentes).

Queda pues abierto el diálogo. 


\section{Bibliografia}

ARribas, A. (1968): "Las bases económicas del Neolítico al Bronce», Estudios de economia antigua de la Península Ibérica, Barcelona.

ARribAs, A. Y OTros (1974): Excavaciones en el Cerro de la Encina, EAE, n. ${ }^{\circ} 81$, Madrid.

BOESSNECK, J. (1966-68): «Restos óseos de animales del Cerro de la Virgen de Orce y del Cerro del Real", Noticiario Arqueológico Hispánico, X, XI, XII.

CATÁlogo de Suelos de AndaluCia (1984): Monografías del Medio ambiente, 3, Sevilla.

Colmenarejo, M. R. (1986): Arquitectura y urbanismo en la edad del Bronce en la Península lbérica, Memoria de Licenciatura Universidad Autónoma.

Díaz Álvarez, J. R. (1981): Estudio del potencial de los suelos agrarios de la provincia de Almeria, Madrid.

DíAZ ALVAREZ, J. R. (1984): Atlas geográfico provincial comentado de Almeria, Almería.

GILman, A.Y ThORNes, B. (1985): Land use and Prebistory in the south east Spain, The London Research Series in Geography, 8, London.

LULL, V. (1983): La cultura del Argar, Barcelona.

Mapa de Cultivos y Aprovechamientos de la Provincia de Almeria (1982): Escala 1:100.000.

MAPA GeOlÓGICO DE EsPaÑA (1974): Escala 1:50.000, hojas n. 996, 997, 1.014 y 1.015.

MAPA GEOTÉCNICO GENERAL (1976): Almería-Garrucha, escala 1:200.000.

MAPA METAlogenÉtico de EsPaña (1974): Escala 1:200.000.

MAPA TOPOGRÁFICO NACIONAL (1963): Escala 1:50.000, hojas n. $.^{\circ} 996,997,1.014$ y 1.015.

MENDOZA, A. Y PAREJA, E. (1975): "Cista argárica en Jerez del Marquesado (Granada)", Congreso Nacional de Arqueología XIII, Zaragoza.

NavarRo Mederos, J. F. (1983): «La exploitación del territorio en la Península Ibérica durante el Bronce Pleno. Aproximación a su estudio", Tabona, IV, Universidad de La Laguna.

Pellicer Catalán, M. (1986): “Bronce Antiguo y Medio», Historia de España, Tomo 1. Prehistoria, pág. 307 y ss. Madrid.

Pérez CASAS, A. Y PAOLETTI, C. (1977): «Enterramiento en cista hallado en Gador y poblamiento argárico en el valle del Andarax", Cuadernos de Prehistoria de la Universidad de Granada, n. ${ }^{\circ}$, pág. 213 y ss.

RUBIO RECIO, J. M. (1988): Biogeografia, paisajes vegetales y vida animal, Madrid.

Ruiz Gálvez, M. L. (1977): "Nueva aportación al conocimiento de la Cultura del Argar, Trabajos de Prehistoria, 34, pág. 85 y ss, Madrid.

SCHubart, H. (1973): "Las alabardas tipo Montejicar", Homenaje al doctor Luis Pericot, Publicaciones eventuales, n. ${ }^{\circ} 23,247-269$, Barcelona.

SCHubarT, H. (1975): “Cronología relativa de la Cerámica Sepulcral en la Cultura de el Argar», Trabajos de Prebistoria, 32, pág. 79 y ss. Madrid.

SCHUBART, H.Y ARTEAGA, O. (1978): «Fuente Alamo" Madrider Mitteilungen, 19, págs. 23-51.

SCHUBART, H. Y ARTEAGA, O. (1980): "Fuente Alamo. Excavaciones 1977», Noticiario Arqueológico Hispánico, 9, Madrid.

SChubaRT, H. y ARTEAGA, O. (1981): “Fuente Alamo. Campaña de 1979», Noticiario Arqueológico Hispánico, 11, Madrid.

SCHUBART, H. y ARTEAGA, O. (1983 a, b, c): «Excavaciones en Fuente Alamo: La cultura del Argar", Revista de Arqueología n. ${ }^{\circ} 24,25$ y 26.

SIRET, L. Y E. (1890): Las primeras edades del metal en el Sudeste de España, Barcelona. 